GÜERRI, Cristina; ALARCÓN, Pau: "Calidad de vida de migrantes presos: Diferencias en la percepción de calidad de vida penitenciaria entre migrantes y autóctonos en las prisiones españolas".

Polít. Crim. Vol. 16, № 31 (Junio 2021), Art. 4, pp. 83-114

[http://politcrim.com/wp-content/uploads/2021/04/Vol16N31A4.pdf]

\title{
Calidad de vida de migrantes presos: Diferencias en la percepción de calidad de vida penitenciaria entre migrantes y autóctonos en las prisiones españolas*
}

\section{Imprisoned migrants: Differences in perceived quality of prison life between migrants and natives in Spanish prisons}

\author{
Cristina Güerri \\ Doctora en Derecho por la Universitat Pompeu Fabra \\ Investigadora Posdoctoral Juan de la Cierva-Formación, Universidad de Málaga \\ cristina.guerri@uma.es \\ https://orcid.org/0000-0002-4382-040
}

Pau Alarcón

Doctor en Políticas Públicas por la Universitat Autònoma de Barcelona

Profesor Asociado, Universitat Pompeu Fabra

pau.alarcon@upf.edu

https://orcid.org/0000-0002-7937-9337

\section{Resumen}

Fecha de recepción: 14/06/2020.

Fecha de aceptación: 23/09/2020.

Las personas extranjeras están sobrerrepresentadas en numerosas prisiones de Europa occidental, incluida España. Consecuentemente, existe una preocupación creciente por conocer su situación y garantizar la igualdad de trato en el ámbito penitenciario. Sin embargo, la literatura al respecto en España es escasa y no establece qué problemáticas son comunes a todos los presos y cuáles son específicas de los extranjeros. Nuestro objetivo es comprobar si la vivencia del encarcelamiento difiere entre presos autóctonos y migrantes de cuatro prisiones catalanas mediante el análisis comparativo de sus respuestas al cuestionario MQPL sobre calidad de vida en prisión, combinando dos estrategias metodológicas cuantitativas y apoyándonos en información cualitativa. Concluimos que la administración penitenciaria parece realizar un buen trabajo a la hora de proporcionar igualdad de trato, pues la valoración de los presos migrantes de su calidad de vida no es peor que la de los nacionales, aunque se advierten mayores dificultades para la progresión penitenciaria que deberían corregirse. Asimismo, se muestra la importancia de diferenciar entre colectivos de migrantes en el desarrollo de las políticas penitenciarias, pues ello permite un mejor reconocimiento de sus

\footnotetext{
* Esta investigación se inscribe en el proyecto "Ejecución y supervisión de la pena: Calidad de la intervención, legitimidad y reincidencia". Financiado por MINECO (Ref. DER2015-64403-P) y FEDER, UE. Agradecemos a la Direcció General de Serveis Penitenciaris de la Generalitat de Catalunya por habernos facilitado el acceso a los centros penitenciarios objeto de la presente investigación y al personal que trabaja en cada uno de ellos por habernos ayudado en todo momento. Asimismo, también queremos agradecer a las dos personas que efectuaron la revisión de este artículo por la calidad y el detalle de los comentarios y anotaciones que hemos recibido.
} 
necesidades como grupo no homogéneo $\mathrm{y}$, por tanto, una mejor respuesta frente a la necesidad de un trato igualitario.

Palabras clave: prisión, migrantes presos, calidad de vida, política penitenciaria, análisis cuantitativo.

\begin{abstract}
Foreigners are overrepresented in most Western European prisons, including Spain. For this reason, there has been a growing interest in studying the conditions of detention for foreigners in European prisons and granting that international standards on equal treatment are met. Notwithstanding, previous literature on the living conditions of foreign prisoners in Spain is scarce and it does not distinguish if the problems identified are common to every prisoner or they only affect non-natives. Therefore, our goal is to test if quality of prison life differs between native and migrant prisoners in four Spanish prisons. For this purpose, we compare the answers of both groups to the Measuring Quality of Prison Life survey. Our results show that the studied prisons seem to be providing equal treatment to native and migrant prisoners, although the latter face more difficulties for sentence progression that should be addressed. Moreover, it is argued that differences among groups of migrants should be considered when implementing penitentiary policies since recognizing their needs as a non-homogeneous group allows for providing equal treatment.
\end{abstract}

Keywords: prison, migrant prisoners, quality of life, penitentiary policy, quantitative analysis

\title{
Introducción
}

Los ciudadanos extranjeros están sobrerrepresentados en las prisiones españolas: según datos de la Secretaría General de Instituciones Penitenciarias, en julio de 2019 los extranjeros representaban un 24,7\% del total de presos en la Administración General del Estado, mientras que la población extranjera según el Instituto Nacional de Estadística supone el 10,7\% del total en esa misma fecha. En el caso de la administración penitenciaria catalana, la otra administración penitenciaria de España, ${ }^{1}$ la cifra de extranjeros en prisión ascendía al 45,5\%, en contraste con el $15,1 \%$ de extranjeros entre la población total. ${ }^{2}$ Esta sobrerrepresentación

\footnotetext{
1 En el momento de publicarse este artículo, existen dos administraciones penitenciarias en España: la Administración General del Estado, que comprende todas las Comunidades Autónomas a excepción de Cataluña, y la administración penitenciaria catalana, la cual gestiona las prisiones de su territorio. Sin embargo, el lector debe saber que próximamente Euskadi también va a asumir la gestión de la actividad penitenciaria en su territorio. SEGOVIA (2020), passim.

${ }^{2}$ Según los datos del Instituto Nacional de Estadística y del Ministerio de Interior, la tendencia de la población extranjera (censada y reclusa) en España ha sido creciente desde el año 2000, coincidiendo con la llegada de la inmigración al país. Este crecimiento constante alcanzó su pico en 2009 (atendiendo a los números absolutos de población extranjera censada y reclusa) o en 2010-2011 (según el porcentaje de extranjeros sobre el total de internos). Desde ese momento, la población extranjera (censada y reclusa) ha ido en general en descenso. En la Administración General del Estado se ha visto asimismo reducido el porcentaje de extranjeros en prisión (que
} 


\section{Polít. Crim. Vol. 16, No 31 (Junio 2021), Art. 4, pp. 83-114 [http://politcrim.com/wp-content/uploads/2021/04/Vol16N31A4.pdf]}

resulta más evidente cuando presentamos los datos en forma de tasa de encarcelamiento: en la Administración General del Estado hay 316,4 ciudadanos extranjeros encarcelados por cada 100.000 habitantes extranjeros, triplicando la tasa de presos nacionales $(107,5$ por cada 100.000 españoles), ratio que llega a ser 5 veces mayor en Cataluña (362,8 frente al 70,4, respectivamente). ${ }^{3}$

Esto no sucede solo en España. Si bien la proporción de extranjeros encarcelados varía entre países, del $11,1 \%$ de Inglaterra y Gales, al $54,7 \%$ de Austria, ${ }^{4}$ se constata una tendencia común: las personas extranjeras están sobrerrepresentadas en la mayoría de las prisiones de Europa occidental y su proporción ha ido en constante aumento desde hace dos décadas. ${ }^{5} \mathrm{En}$ consecuencia, ha surgido una preocupación creciente en la literatura internacional por conocer la situación de los presos extranjeros en las prisiones europeas y las dificultades específicas que tienen que afrontar, ${ }^{6}$ especialmente a raíz de la creación de prisiones exclusivas para extranjeros en países como Inglaterra y Gales, Noruega o los Países Bajos, cuyo régimen podría estar vulnerando el principio de no discriminación. ${ }^{7}$

En España existe numerosa literatura orientada a abordar la sobrerrepresentación de la población extranjera en el sistema penitenciario, la cual no es explicada por una mayor actividad delictiva de los migrantes ${ }^{8}$ sino por la mayor selectividad de un sistema penal cada vez más empleado como herramienta de control de la inmigración. ${ }^{9}$ Desde esta perspectiva, se señala que la ley de extranjería, la cual atribuye un estatuto jurídico diferenciado al migrante (admitiéndolo únicamente si hay necesidades laborales y previendo respuestas materialmente penales - de internamiento y expulsión para quienes se encuentren en el país de manera irregular), en conjunción con discursos mediáticos y políticos que asocian inmigración y delincuencia, han creado la imagen del migrante como sujeto de riesgo, ${ }^{10} \mathrm{y}$ que ello comporta una mayor actuación del sistema penal sobre los migrantes en sus distintas fases — policial, judicial y penitenciaria — y, por ende, una mayor entrada de migrantes en el sistema penitenciario. ${ }^{11}$

Asimismo, la literatura española también ha constatado diversos ámbitos en que los migrantes se ven perjudicados en la práctica penitenciaria, principalmente por la utilización

alcanzó a ser del 34,4\% en 2010), mientras que en Cataluña esta proporción se ha mantenido más estable, oscilando entre el $44 \%$ y el $46 \%$.

${ }^{3}$ Cálculo efectuado por los autores a partir de datos a julio de 2019 de la Secretaría General de Instituciones Penitenciarias y del Instituto Nacional de Estadística. Debe advertirse que estas cifras pueden resultar algo engañosas al compararse dos colectivos con una composición demográfica y socioeconómica diferente. En este sentido, si controlásemos aspectos como la edad, la clase social o el lugar de residencia las diferencias, si bien seguirían existiendo, serían menores. ESCOBAR (2010), pp. 270-272.

${ }^{4}$ Datos a 31 de enero de 2019. AEBI y TIAGO (2020), p. 63 (Tabla 13).

${ }^{5}$ VAN KALMTHOUT et al. (2007), pp. 7-90; AEBI et al. (2019), p. 5.

${ }^{6}$ Por ejemplo, VAN ZYL SMIT y SNACKEN (2013), pp. 288-289; UGELVIK (2015), pp. 107-120.

${ }^{7}$ KAUFMAN (2012), pp. 701-702; PAKES y HOLT (2017), pp. 68-72; MULGREW (2018), pp. 77-80.

${ }^{8}$ GARCÍA-ESPAÑA (2001), passim; GARCÍA-ESPAÑA (2018a), pp. 45-60.

${ }^{9}$ Por ejemplo, DAUNIS (2009), pp. XIX-XXIII y pp. 23-31; BRANDARIZ (2011), 148-154.

${ }^{10}$ BRANDARIZ y FERNÁNDEZ-BESSA (2010), pp. 275-279; BRANDARIZ (2011), pp. 9-80; GONZÁLEZ SÁNCHEZ (2016), pp. 125-129.

${ }^{11}$ MONCLÚS (2008), pp. 257 y ss.; BRANDARIZ (2011), pp. 104-147; GONZÁLEZ SÁNCHEZ (2016), pp. 130-136. 
del concepto de arraigo para determinar el riesgo de fuga. ${ }^{12}$ Los efectos de esta práctica se observan, por ejemplo, en las cifras de prisión preventiva: en 2018, uno de cada cuatro extranjeros presos estaba en situación de preventiva, frente a uno de cada diez españoles. ${ }^{13}$ Asimismo, diversas investigaciones señalan, por estas mismas razones, una menor concesión de permisos de salida ${ }^{14} \mathrm{y}$, en consecuencia, un menor acceso a mecanismos de reinserción como el tercer grado ${ }^{15}$ y la libertad condicional. ${ }^{16}$ En suma, el criterio de arraigo opera de tal manera que hay numerosos migrantes encarcelados sin haber sido condenados $y$ favoreciendo que aquellos que ya han sido condenados cumplan la condena de forma íntegra, y ello engrosa la proporción de no nacionales encarcelados.

En conjunto, estas investigaciones sugieren que los migrantes entran más en prisión y cumplen la condena de forma íntegra en mayor proporción que los españoles. ${ }^{17} \mathrm{Sin}$ embargo, la literatura relativa a cómo estas personas experimentan el encarcelamiento es escasa.

${ }^{12}$ Desde un punto de vista legal, la falta de arraigo se asocia a una probabilidad mayor de fuga al entenderse que quien no tiene familia o domicilio conocido en España no tiene motivos para permanecer en el país. Aunque este argumento puede resultar convincente, lo cierto es que, aun no siendo un criterio diseñado para perjudicar a los migrantes, genera una discriminación sistemática hacia este colectivo, el cual no encaja en un modelo de prisión diseñado pensando en presos hombres y de nacionalidad española. GONZÁLEZ SÁNCHEZ (2016), p. 135.

${ }^{13}$ Estos datos son ciertos tanto para la Administración General del Estado, véase Informe General 2018 de la Secretaría General de Instituciones Penitenciarias, p. 58, como para la administración penitenciaria catalana, véase la información disponible en los Descriptores Estadísticos de Servicios Penitenciarios del Departamento de Justicia de Cataluña. Se han proporcionado los datos de 2018 porque es el dato más reciente disponible para la Administración General del Estado.

${ }^{14}$ Los permisos penitenciarios permiten la salida temporal del centro penitenciario durante un máximo de siete días, con un límite anual de treinta y seis días. La investigación empírica (véanse ROVIRA et al. (2018), pp. 14-15, o IBÀÑEZ (2019), p. 22) muestra una menor concesión de estos permisos de salida a las personas extranjeras.

${ }^{15}$ Para lograr el fin constitucional de la reeducación y la reinserción de los penados (artículo 25.2 de la Constitución Española), el sistema penitenciario español se estructura en base a la idea de la progresión de la pena (artículo 75 de la Ley Orgánica General Penitenciaria) y prevé tres grados de tratamiento que se corresponden con tres regímenes de vida diferentes. El tercer grado equivale al régimen abierto (artículo 74 del Reglamento Penitenciario), esto es, un estadio de semilibertad en el cual la persona presa puede salir durante el día a desempeñar actividades laborales o de cuidado y solo debe retornar al centro penitenciario para pernoctar. La clasificación en tercer grado es discrecional y depende de la Junta de Tratamiento del centro penitenciario. Investigaciones empíricas desarrolladas en Cataluña, como CENTRO DE ESTUDIOS JURÍDICOS Y FORMACIÓN ESPECIALIZADA, en adelante, CEJFE (2014), p. 129, e IBÀÑEZ (2019), p. 22, muestran que las personas extranjeras experimentan más dificultades para ser clasificadas en tercer grado que las españolas. Véase también GARCÍA-ESPAÑA et al. (2012), pp. 132, quienes ofrecen datos para el conjunto de España.

${ }^{16}$ CEJFE (2004), pp. 93-95; CEJFE (2014), p. 115.

${ }^{17}$ Otro conjunto de estudios muestra las consecuencias de la legislación española de extranjería sobre los migrantes que salen de prisión, tales como la imposibilidad de obtener el permiso de residencia por tener antecedentes penales (véase LARRAURI (2016), pp. 6-11) o el ser deportados tras cumplir condena por medio de "expulsiones cualificadas" asociadas a esos antecedentes penales (véanse FERNÁNDEZ-BESSA y BRANDARIZ (2016), pp. 9-13; LARRAURI (2016), pp. 16-19). Sin embargo, esta cuestión queda fuera del ámbito de análisis del presente trabajo.

El Ministerio del Interior de España emplea el término "expulsiones cualificadas" en los Balances anuales para la lucha contra la inmigración irregular para referirse a aquellas expulsiones vinculadas a la comisión de delitos (véase, por ejemplo, la Nota de prensa del Ministerio del Interior de 29 de abril de 2014). A este respecto, BRANDARIZ y FERNÁNDEZ-BESSA (2017), pp. 129-130, señalan que no se trata de un tipo específico de 


\section{Polít. Crim. Vol. 16, № 31 (Junio 2021), Art. 4, pp. 83-114 [http://politcrim.com/wp-content/uploads/2021/04/Vol16N31A4.pdf]}

Por una parte, dos estudios han incluido preguntas relativas a la percepción de los extranjeros de la vida en prisión en el marco de investigaciones más amplias. Estas investigaciones ofrecen información descriptiva sobre las problemáticas identificadas por los encuestados. ${ }^{18}$ Por otra, diversas investigaciones cualitativas recogen y analizan las vivencias subjetivas de extranjeros presos en España. ${ }^{19}$

No obstante, estas investigaciones presentan dos tipos de limitaciones. En primer lugar, se centran exclusivamente en la percepción subjetiva del extranjero (cómo percibe su vida en prisión y cómo cree que esta se diferencia, para mejor o para peor, de la de los presos españoles), impidiendo identificar qué problemáticas son comunes a todos los presos y cuáles son específicas de los extranjeros. Por ejemplo, en la investigación del Centro de Estudios Jurídicos y Formación Especializada, casi la mitad de los internos de terceros países manifiesta que el ambiente en prisión es tenso $(47,7 \%)$ y que les resulta muy difícil hacer que el tiempo pase en prisión $(42,1 \%),{ }^{20}$ pero sin discernir si estas malas experiencias son inherentes al encarcelamiento y compartidas por todos los presos independientemente de su nacionalidad o si, por el contrario, estos sufrimientos se ven acentuados o se explican por el solo hecho de ser extranjeros.

En segundo lugar, realizan generalizaciones sobre un colectivo heterogéneo, 'los extranjeros', ${ }^{21}$ en vez de diferenciar entre colectivos de extranjeros que pueden presentar especificidades en cuanto a sus condiciones de encierro en prisión. ${ }^{22}$ Es cierto, como señala Bhui, ${ }^{23}$ que los extranjeros presos pueden experimentar dificultades similares derivadas del proceso migratorio y el estatus de no nativos, tales como problemas para mantener el contacto con la familia, el estar sujetos a la legislación de extranjería o la falta de familiaridad con el idioma y/o la cultura autóctona. No obstante, si consideramos que las nacionalidades más presentes en las prisiones españolas son las de países latinoamericanos (con quienes compartimos lengua materna), la rumana (quienes son ciudadanos comunitarios) y la marroquí (quienes ni pertenecen al espacio europeo ni comparten el español como lengua materna), resulta evidente que sus experiencias y necesidades pueden variar en numerosos sentidos. En concreto, los presos de Marruecos suponen un 23,7\% del total de extranjeros en las prisiones españolas, los de Rumanía un 10,8\% y los dos países latinoamericanos con mayor representación son Colombia y Ecuador, con un $9,6 \%$ y un $4 \%$ respectivamente. $^{24}$

expulsiones, sino más bien de una retórica que pretende legitimar dichas expulsiones dotándolas de una carga simbólica vinculada a semánticas de peligrosidad y seguridad.

${ }^{18}$ GALLEGO et al. (2010), pp. 77-85; CEJFE (2010), pp. 170-177.

19 Véanse CASTILLO y RUIZ-GARCÍA (2010), passim; AGUDO (2012), passim; RUIZ-GARCÍA y CASTILLO (2014), passim, sobre mujeres extranjeras presas en España; y MONTERO y DURNESCU (2016), passim, sobre presos rumanos en dos centros penitenciarios españoles.

${ }^{20}$ CEFJE (2010), pp. 173-174.

${ }^{21}$ GONZÁLEZ SÁNCHEZ (2016), pp. 133-134.

${ }^{22}$ No obstante, GALLEGO et al. (2010), p. 79, sí cruzan sus datos con la nacionalidad y MONTERO y DURNESCU (2016), passim, al focalizarse en los presos rumanos, evitan caer en las generalizaciones a las que hacemos referencia.

${ }^{23}$ BHUI (2009), p. 166.

${ }^{24}$ MINISTERIO DEL INTERIOR (2019), p. 312. 
Consideramos necesario, por tanto, introducir esta distinción para constatar si hay diferencias en la percepción de calidad de vida penitenciaria entre los colectivos de migrantes. ${ }^{25}$

Esta investigación, enmarcada en el proyecto sobre calidad de vida penitenciaria desarrollado por el Grupo de Investigación en Criminología y Sistema Penal de la Universitat Pompeu Fabra, pretende superar estas limitaciones y contribuir al conocimiento sobre cómo los migrantes experimentan el encarcelamiento en España. Para ello, se compara la percepción de la calidad de vida en prisión de los distintos grupos de migrantes presos con la de los autóctonos. Concretamente, se persiguen dos objetivos: 1) conocer si la vivencia del encarcelamiento difiere entre presos autóctonos y migrantes en aquellos factores relevantes para la calidad de vida en prisión y 2) testar la importancia de no tratar a los migrantes como un colectivo homogéneo. ${ }^{26}$

El presente trabajo se estructura del siguiente modo: en primer lugar, se desarrolla el marco teórico, identificando los diferentes elementos a tener en cuenta para analizar la percepción de la calidad de vida en prisión, así como una revisión de la literatura sobre las dificultades específicas que pueden afrontar los presos extranjeros. En segundo lugar, se detalla la metodología utilizada, describiendo la muestra del estudio, los ítems de la encuesta utilizados (variables dependientes e independientes) y las técnicas de análisis. En tercer lugar, se muestran los resultados obtenidos mediante dos análisis complementarios. A continuación se desarrolla una discusión para interpretar los hallazgos obtenidos. Por último, en las conclusiones se apuntan las implicaciones del estudio y algunas reflexiones más generales.

\section{Marco teórico}

\subsection{Calidad de vida en prisión}

El estudio sociológico de la prisión se inicia en los años cuarenta y cincuenta del siglo XX en Estados Unidos con el objetivo de analizar cómo se organizan las 'comunidades' o 'sociedades' de reclusos para lidiar con los efectos negativos de la institución penitenciaria. ${ }^{27}$ Sin embargo, con el tiempo se ha llegado al consenso de que no existe una única prisión, sino

\footnotetext{
${ }^{25}$ En los análisis efectuados en este artículo empleamos la categoría 'migrante' para referirnos a aquellas personas que reportaron haber nacido fuera de España. El motivo es que queremos poner énfasis en cómo el estatus de no-nativo de las personas migrantes (falta de capital social y cultural) puede influir en el trato que perciben y, por tanto, en su valoración de la calidad de vida en prisión. Aunque somos conscientes de que empleando el lugar de nacimiento nuestra categoría podría capturar a personas que no encajarían en la definición estricta de migrante, consideramos importante pivotar sobre la idea de los migrantes presos porque son ellos quienes reúnen las características sociales, económicas, jurídicas y políticas de precariedad que los convierten en una 'clase peligrosa' sobre la que actúa el sistema de control penal; BRANDARIZ (2011), p. 6.

${ }^{26}$ La investigación de SALES (2018), passim supone un primer paso en esta línea, empleando los datos recogidos en el Centro Penitenciario de Lledoners. El presente artículo amplía la investigación con la información recogida en el marco del mismo proyecto de investigación en los cuatro centros penitenciarios cerrados de la provincia de Barcelona.

27 Véanse las célebres obras de CLEMMER (1940), passim y SYKES (1958[2007]), passim, quienes las denominaron 'La comunidad penitenciaria' (The prison community) y 'La sociedad de los cautivos' (The society of captives), respectivamente.
} 


\section{Polít. Crim. Vol. 16, No 31 (Junio 2021), Art. 4, pp. 83-114 [http://politcrim.com/wp-content/uploads/2021/04/Vol16N31A4.pdf]}

que estas difieren en cuanto a su gestión y organización, y que ello influye determinantemente en cómo se experimenta el encarcelamiento. ${ }^{28}$

Con el fin de medir estas diferencias y determinar qué es importante en términos de calidad de vida de los presos, se han desarrollado numerosos instrumentos evaluativos, siendo la encuesta Measuring Quality of Prison Life (MQPL) una de las más empleadas en la actualidad. ${ }^{29}$ Este cuestionario fue desarrollado por el Prison Research Center del Instituto de Criminología de Cambridge mediante numerosas entrevistas con personas presas para medir la calidad de vida en prisión desde su perspectiva. ${ }^{30}$ Una de las particularidades de esta encuesta es que no se limita a valorar las condiciones materiales del encierro sino que también intenta capturar el 'desempeño moral' (moral performance) de cada prisión.

Tras implementar la MQPL en las prisiones catalanas, la investigación constata que la organización de cada centro penitenciario y la calidad de las relaciones resultan más determinantes que las características de las personas presas para explicar su percepción de la calidad de vida en prisión. ${ }^{31}$ Concretamente, respecto a la organización de las prisiones, se demuestra que, si bien el estándar de vida tiene relevancia, una buena planificación de actividades y el apoyo para planificar la futura puesta en libertad son especialmente importantes para percibir una buena calidad de vida en prisión. Asimismo, en cuanto a las relaciones, se observa que el trato proporcionado por el personal y la conflictividad entre internos influyen considerablemente en esa percepción de la calidad de vida de los presos. ${ }^{32}$

\subsection{Dificultades específicas de los migrantes presos}

La literatura sugiere que los migrantes presos experimentan dificultades específicas asociadas tanto a su estatus legal de extranjeros como a su estatus de no-nativos (falta de capital social y cultural), las cuales podrían repercutir negativamente en su percepción de la calidad de vida en prisión. De hecho, la preocupación por el elevado número de extranjeros en las prisiones europeas y el reconocimiento de sus dificultades específicas llevaron al Consejo de Europa a elaborar la Recomendación CM/Rec(2012)12 del Comité de Ministros a los Estados miembros relativa a los presos extranjeros (en adelante, "Rec(2012)12").

A continuación, ponemos en relación las principales dificultades señaladas por la literatura internacional con cada uno de los elementos identificados como relevantes para la calidad de vida en prisión y con las recomendaciones que la $\operatorname{Rec}(2012) 12$ realiza para tratar de superarlas.

\footnotetext{
${ }^{28}$ Véase, por ejemplo, el clásico de DOWNES (1988), passim, Contrasts in tolerance, comparando los sistemas penitenciarios de Países Bajos e Inglaterra y Gales.

${ }^{29}$ Para una explicación detallada de los diversos instrumentos evaluativos empleados en el estudio de la calidad de vida en prisión en España y en el contexto internacional, véase MARTÍ (2017), pp. 4-24.

${ }^{30}$ Para una explicación detallada acerca del cuestionario y la metodología empleada para desarrollarlo, véase LIEBLING (2004), passim.

${ }^{31}$ RODRÍGUEZ et al. (2018), pp. 14-15.

${ }^{32}$ La MQPL también ha sido implementada en diversas prisiones de la Administración General del Estado arrojando resultados similares; véanse BARQUÍN et al. (2016), passim; (2019), passim; POZO et al. (2018), passim; (2020), passim; CUTIÑO et al. (2019), passim.
} 


\subsubsection{Estándar de vida}

Las diferencias culturales entre el país de origen y aquel donde se cumple condena pueden dificultar la adaptación a la vida en prisión e influir en la calidad de vida percibida. En este sentido, la $\operatorname{Rec}(2012) 12$ sugiere prestar especial atención a que las condiciones de higiene y la comida respeten la diversidad cultural (Recomendaciones 18 y 20, respectivamente) y que la atención médica de los extranjeros sea igual que la de los nacionales (Recomendación 31.1).

Uno de los elementos culturales que más echan de menos los internos migrantes es la comida. ${ }^{33}$ Así, aquellas prisiones que permiten a los internos cocinar suelen estar muy bien valoradas por los presos extranjeros, además de fomentar lazos entre culturas y la convivencia en el centro. ${ }^{34}$

En cuanto a la atención médica, no todos los países ofrecen las mismas posibilidades a nacionales que a extranjeros. Mientras algunos países como Noruega cumplen la recomendación del Consejo de Europa, otros como la República Checa obligan a los presos extranjeros a costearse la asistencia sanitaria que no sea de urgencia. ${ }^{35}$

En España, las presas extranjeras entrevistadas en una investigación se quejaban de la poca frecuencia de la atención médica ${ }^{36}$ y en otro estudio desarrollado en la Administración General del Estado, la comida fue señalada por 1 de cada 5 internos extranjeros como una dificultad añadida de su día a día en comparación con los presos españoles. ${ }^{37}$

No obstante, en las prisiones españolas la asistencia médica es universal ${ }^{38}$ y la administración catalana ha promovido el respeto de la diversidad de creencias en instituciones penitenciarias, lo cual incluye medidas tales como proporcionar menús adaptados a las necesidades religiosas de los presos o prever que pueden requerir acceso a las celdas para asearse de forma previa a la oración. ${ }^{39}$ Por ello, consideramos que no existen razones para esperar que los extranjeros valoren peor la higiene, la comida o la atención médica en nuestro estudio.

\subsubsection{Actividades: ocupación del tiempo, educación y formación, programas de tratamiento}

La Rec(2012)12 establece que los internos de terceros países deben tener igual acceso a un programa equilibrado de actividades, esencial para vencer la monotonía de la vida en prisión. También explicita que la participación en dichas actividades no puede verse restringida ni siquiera si el preso está en proceso de expulsión (Recomendación 26.1).

\footnotetext{
${ }^{33}$ UGELVIK (2011), pp. 57-58; BEYENS y BOONE (2015), pp. 489-490.

${ }^{34}$ PHILLIPS (2012), pp. 88-89.

35 UGELVIK (2015), pp. 116.

${ }^{36}$ RUIZ-GARCÍA y CASTILLO (2014), p. 595.

${ }^{37}$ GALLEGO et al. (2010), p. 78.

${ }^{38}$ RODRÍGUEZ YAGÜE (2004), pp. 22-24.

${ }^{39}$ DEPARTAMENT DE JUSTÍCIA (2015), pp. 34-47 y 78-145.
} 


\section{Polít. Crim. Vol. 16, No 31 (Junio 2021), Art. 4, pp. 83-114 [http://politcrim.com/wp-content/uploads/2021/04/Vol16N31A4.pdf]}

A pesar de ello, la literatura muestra que en numerosos países esto no se cumple. Por ejemplo, en Inglaterra y Gales hay evidencia de un menor acceso de los extranjeros a los programas de tratamiento, lo cual es atribuido tanto a dificultades idiomáticas como que muchos de ellos no eran considerados para dichos programas. ${ }^{40}$ De forma similar, una investigación comparada en prisiones exclusivas para extranjeros de Países Bajos y Noruega identifica una peor oferta de actividades, puesto que en estas prisiones no se organizan actividades por las tardes o se permite menor tiempo fuera de la celda, respectivamente. ${ }^{41}$

\subsubsection{Apoyo en la reinserción}

La condición de extranjero no solo afecta a las actividades a las que pueden acceder para su rehabilitación, también repercute negativamente en el apoyo que reciben para su posterior reinserción. Esto se manifiesta tanto en la ayuda para la preparación de su futura vida en libertad como en el acceso a los mecanismos de progresión penitenciaria.

Investigaciones desarrolladas en Inglaterra y Gales muestran que los extranjeros reciben menos apoyo en este sentido en comparación con los nacionales británicos por ser elegibles para ser expulsados del país y, por tanto, no existir perspectiva real de reinserción..$^{42}$ Esta falta de apoyo perjudica la calidad de vida de los migrantes al negarles la posibilidad de desarrollar una narrativa de desistimiento y generar una 'privación de esperanza'. ${ }^{43}$

En esta línea, a los extranjeros se les conceden y aplican en menor medida, o con mayor lentitud, los permisos de salida y los mecanismos de progresión como el régimen abierto. ${ }^{44}$ Estas mayores dificultades para conseguir progresar en el modo de cumplimiento de condena o tener más contacto con el exterior puede generar sentimientos de frustración e injusticia en los internos extranjeros, que ven cómo se quedan atrás por el hecho de no tener la nacionalidad del país donde están presos, generando una 'privación de legitimidad' respecto de la pena impuesta. ${ }^{45}$

Otras investigaciones señalan que la falta de capital cultural de los presos extranjeros también podría repercutir negativamente en el apoyo recibido para su reinserción. Así, las dificultades idiomáticas para comunicarse con el personal, ${ }^{46}$ el desconocimiento de la subcultura carcelaria y saber hasta qué punto es admisible o no establecer relaciones con el personal ${ }^{47} \mathrm{o}$ una mayor desconfianza respecto a este ${ }^{48}$ puede disminuir el acceso al apoyo que este colectivo podría prestarles y dificultar la progresión en su itinerario de reinserción.

\footnotetext{
${ }^{40}$ HMIP (2006), citado en BHUI (2007), pp. 373-374.

${ }^{41}$ MULGREW (2018), pp. 80-81.

${ }^{42}$ BHUI (2004b), pp. 36-37 y 44; BHUI (2007), pp. 373-375.

${ }^{43}$ Esta 'privación de esperanza', WARR (2016), pp. 313-314, se da con respecto al curso de sus vidas, ya sea en la misma prisión o ante una eventual salida.

${ }^{44}$ A las investigaciones sobre esta cuestión en España, explicadas previamente, podemos añadir investigaciones en otros contextos como la de BHUI (2004b), pp. 36-37; (2007), pp. 374-375, quien señala las dificultades de los extranjeros presos en centros penitenciarios de Inglaterra y Gales para conseguir permisos de salida (release on temporary licence) o la clasificación en prisiones abiertas (Category D prisons).

45 WARR (2016), pp. 310-313.

46 BHUI (2004a), p. 10; (2009), p. 159; BEYENS y BOONE (2015), pp. 487-488.

${ }^{47}$ MONTERO y DURNESCU (2016), p. 38.

${ }^{48}$ HMIP (2010), citado en KRUTTSCHNITT et al. (2013), p. 482.
} 
En este sentido, el énfasis de la Rec(2012)12 en garantizar el igual acceso a un programa equilibrado de actividades, entronca con su efecto positivo de cara a la reinserción.

\subsubsection{Relaciones con el personal}

Relacionado con el punto anterior, vemos que el trato que brindan los funcionarios es relevante para la calidad de vida. Esta puede empeorar si los migrantes perciben que están recibiendo un trato discriminatorio por el hecho de no ser autóctonos. Esta percepción de discriminación por parte del personal puede darse en dos niveles: sentir que están siendo tratados con menos respeto o que están siendo perjudicados cuando se toman decisiones sobre ellos. $^{49}$

Respecto al trato recibido, Bhui ${ }^{50}$ señala que el racismo y la falta de respeto del personal era un tema recurrente en los relatos de los presos extranjeros en prisiones inglesas y que, de hecho, muchos indicaron que la discriminación y el racismo era el problema principal que afrontaban como extranjeros en prisión. Los datos disponibles para España sugieren que el problema del racismo podría no ser tan acusado, pues esta misma pregunta fue incluida en el cuestionario utilizado en las prisiones de la Administración General del Estado y la proporción de extranjeros que indicó que el racismo de los funcionarios era un problema añadido fue de un $16,9 \% .^{51}$

Es importante precisar que este sentimiento de discriminación racista reportado por los presos extranjeros no debe ser vinculado únicamente a quienes pertenecen a minorías étnicas. Una investigación sobre la intersección entre la raza y el estatus de no nativos de holandeses presos en Inglaterra concluye que ambos factores definen la experiencia carcelaria de los presos holandeses pertenecientes a una minoría étnica. ${ }^{52}$ Sin embargo, también se observa que algunos holandeses blancos reportaban haber recibido un trato racista por parte del personal debido a su estatus de no autóctonos (outsiders), indicando que el origen nacional de los presos también es fuente de discriminación. De forma similar, en un estudio sobre la 'prisión multicultural' inglesa se explica que numerosos presos señalaban haber sido víctimas de epítetos racistas por su etnia, pero que algunos comentarios ofensivos como "vete a tu país" estaban reservados para los presos de origen extranjero. ${ }^{53}$ Finalmente, en Noruega, los extranjeros presos en Kongsvinger, prisión exclusiva para no nacionales, también tildaban al

\footnotetext{
${ }^{49}$ Hay quienes argumentan que la vivencia de la prisión de los extranjeros que pertenecen a una minoría étnica será sustancialmente distinta de la de aquellos que solo ostentan el estatus de no autóctonos (outsiders), frente a quienes defienden que el rasgo definitorio es el estatus de no-nativo (para mayor detalle, ver KRUTTSCHNITT et al. (2013), pp. 482-483). En nuestro caso no es posible debatir esta cuestión puesto que nuestra base de datos no recoge la etnia de los entrevistados. También debemos considerar que entre los nacidos en España habrá personas de etnia gitana e hijos de inmigrantes que podrían sufrir las mismas dificultades que los originarios de terceros países pertenecientes a minorías étnicas.

${ }^{50}$ BHUI (2004a), p. 11.

${ }^{51}$ GALLEGO et al. (2010), p. 78.

${ }^{52}$ KRUTTSCHNITT et al. (2013), pp. 489-492.

${ }^{53}$ PHILLIPS (2012), p. 175.
} 


\section{Polít. Crim. Vol. 16, No 31 (Junio 2021), Art. 4, pp. 83-114 [http://politcrim.com/wp-content/uploads/2021/04/Vol16N31A4.pdf]}

personal de racista porque sentían que no se preocupaban por ellos por el mero hecho de ser extranjeros. $^{54}$

En lo relativo a la discriminación al tomar decisiones, una investigación desarrollada en España reporta que algunos presos de nacionalidad rumana se sienten discriminados en cuestiones como la asignación de 'destinos ${ }^{55} \mathrm{o}$ la concesión de permisos de salida. ${ }^{56}$ Este sentimiento de discriminación es todavía más acentuado en los extranjeros presos en Kongsvinger a los que hacíamos alusión en el párrafo anterior, pues el hecho de estar encarcelados en una prisión exclusiva para extranjeros les señala como outsiders y, en consecuencia, sienten una privación relativa al creer que sus condiciones de vida y actividades formativas son peores que las del resto de las prisiones. ${ }^{57}$

\subsubsection{Convivencia entre presos}

Las diferencias culturales pueden comportar problemas de convivencia entre presos, cuando las normas de interacción social no son compartidas por los distintos grupos. Por ejemplo, esta dinámica es especialmente significativa en el caso de mujeres extranjeras que trataron de introducir drogas en España y fueron detectadas en el aeropuerto, siendo por tanto la prisión lo único que conocen de España. ${ }^{58}$

Un estudio sobre la experiencia de los internos de nacionalidad holandesa en las prisiones inglesas ${ }^{59}$ sostiene que el estatus de no-nativo y los elementos asociados a este dificultan las estrategias de mitigación de los sufrimientos del encarcelamiento descritos por Sykes. ${ }^{60}$ En este sentido, se argumenta que los internos extranjeros, dado que tienden a pasar la condena de manera más individual y relacionarse menos en grupo, tienen menos acceso a estrategias colectivas de mitigación de las privaciones inherentes al encarcelamiento lo cual conlleva que, por ejemplo, la privación de seguridad que experimentan sea mayor. ${ }^{61}$ De hecho, una investigación sugiere que el relativamente alto número de conversiones al Islam observado en algunas prisiones de máxima seguridad inglesas se relaciona con la búsqueda de seguridad a través de la solidaridad de grupo. ${ }^{62}$

Las investigaciones que abordan esta cuestión en España proporcionan evidencia en ambos sentidos. Por una parte, Agudo reporta que algunas presas extranjeras identifican actitudes discriminatorias y cierta conflictividad en relación con las presas españolas, pero también observa comportamientos solidarios entre las presas extranjeras para hacer frente "a las

\footnotetext{
${ }^{54}$ UGELVIK y DAMSA (2018), pp. 1029-1032.

55 Los 'destinos' son puestos de trabajo ocupacional no productivo en servicios auxiliares de los establecimientos penitenciarios como pueden ser la cocina, el economato o la lavandería.

${ }^{56}$ MONTERO y DURNESCU (2016), p. 37.

${ }^{57}$ UGELVIK y DAMSA (2018), pp. 1029-1032.

${ }^{58}$ CASTILLO y RUIZ-GARCÍA (2010), p. 480.

${ }^{59}$ KRUTTSCHNITT et al. (2013), p. 494.

${ }^{60}$ SYKES (1958[2007]), pp. 63-83.

${ }^{61}$ Este mayor sentimiento de inseguridad de los extranjeros presos en Inglaterra y Gales frente a los nacionales británicos fue observado en una visita del organismo de supervisión autónomo Her Majesty's Inspector of Prisons for England and Wales, KRUTTSCHNITT et al. (2013), p. 482.

${ }^{62}$ LIEBLING (2013), p. 218.
} 
adversidades propias de su nacionalidad" ${ }^{63}$ Por la otra, Castillo y Ruiz-García recogen que, a pesar de existir un etiquetamiento colectivo entre internas ('las colombianas', 'las moras'...), no manifiestan que haya actitudes racistas entre ellas que generen problemas de convivencia, al atribuirle una prevalencia al estatus de presa sobre el de nacionalidad. ${ }^{64}$ Asimismo, únicamente un 10,9\% de presos extranjeros de la Administración General del Estado señaló las actitudes racistas de otros presos como un problema añadido ${ }^{65}$ y en Cataluña un 73,5\% de los extranjeros se sentía aceptado por los demás internos. ${ }^{66}$

\subsubsection{Contacto con el exterior}

La literatura muestra que los extranjeros que llegan en el marco de un proyecto migratorio económico y tienen a sus familias en el país de origen experimentan problemas como recibir menos visitas ${ }^{67} \mathrm{y}$ dificultades para realizar llamadas a sus familiares por incompatibilidad de los horarios del establecimiento con la hora en el país de origen, el coste de las llamadas internacionales o la mayor afectación por la corta duración de las llamadas. ${ }^{68}$ Así lo reafirman lo datos disponibles para las prisiones catalanas, los cuales evidencian que los presos españoles reciben más visitas de sus familiares que los extranjeros, siendo las visitas de amigos y profesionales los únicos casos en los que no se aprecian diferencias. ${ }^{69}$ Por ello, la Rec(2012)12 sugiere prestar especial atención al mantenimiento y desarrollo de las relaciones de los presos extranjeros con el mundo exterior (Recomendación 26.2). Estas problemáticas han sido denominadas como 'sufrimientos de las relaciones de larga distancia'. ${ }^{70}$

Por otra parte, esta falta de capital social también puede ir asociada a menos capacidad económica en la prisión. Por ejemplo, en España las presas extranjeras del estudio de Agudo manifestaban problemas en su vida diaria porque, a diferencia de la mayoría de las españolas, sus familias no podían ingresarles dinero en el peculio o enviarles paquetes con ropa de abrigo. ${ }^{71}$ Igualmente, en el estudio de Gallego et al., el 43,1\% de los presos extranjeros señalaron que la falta de recursos era una dificultad que experimentaban en mayor medida que los españoles. ${ }^{72}$

En síntesis, la literatura muestra diversas razones por las cuales el encarcelamiento podría ser experimentado de manera más dura por los presos procedentes de terceros países. No obstante, parte de la evidencia empírica disponible en España sugiere que, en algunos aspectos, estas diferencias podrían no ser tan acentuadas.

\footnotetext{
${ }^{63}$ AGUDO (2012), pp. 89 y ss.

${ }^{64}$ CASTILLO y RUIZ-GARCÍA (2010), pp. 492-493.

${ }^{65}$ GALLEGO et al. (2010), p. 78.

${ }^{66}$ CEJFE (2010), p. 173.

${ }^{67}$ BHUI (2004b), p. 36; BHUI (2007), pp. 372; BHUI (2009), pp. 159-160.

${ }^{68}$ CASTILLO y RUIZ-GARCÍA (2010), pp. 490-491.

${ }^{69}$ CASSÀ (2015), p. 31.

${ }^{70}$ UGELVIK y DAMSA (2018), pp. 1032-1034.

${ }^{71}$ AGUDO (2012), pp. 91-95.

${ }^{72}$ GALLEGO et al. (2010), p. 78.
} 


\section{Polít. Crim. Vol. 16, № 31 (Junio 2021), Art. 4, pp. 83-114 [http://politcrim.com/wp-content/uploads/2021/04/Vol16N31A4.pdf]}

Es más, atendiendo a lo reportado por algunos estudios sobre población extranjera en las cárceles españolas, se puede plantear la hipótesis contraria. Si los presos procedentes de países con condiciones socioeconómicas peores que las de España valoran las condiciones de vida teniendo en mente los estándares que encontrarían en sus países de origen, su satisfacción será, en términos generales, superior a la de los nacionales. En este sentido, el estudio del CEJFE revela que casi la mitad de los internos extranjeros en las prisiones catalanas rechazaría la posibilidad de ser trasladado a una prisión en su país de origen por las condiciones de vida que tendrían ahí. ${ }^{73}$ Del mismo modo, muchas de las internas entrevistadas por Castillo y Ruiz-García se mostraban satisfechas con las condiciones de vida en prisión puesto que, especialmente las que acababan de migrar, esperaban que fueran mucho peores. ${ }^{74}$ Por lo tanto, cabe esperar que, en términos generales, los inmigrantes valoren mejor las condiciones de vida en los centros penitenciarios españoles que los autóctonos, con la excepción de aquellas cuestiones más específicas y en cierto modo objetivables como la concesión de permisos o la recepción de visitas.

La siguiente tabla resume las aportaciones identificadas en la revisión de la literatura. A partir de los diversos estudios y la normativa analizada, se derivan hipótesis respecto a la percepción de la calidad de vida en prisión tanto en términos generales como en relación con los elementos más específicos considerados.

${ }^{73}$ CEJFE (2010), pp. 178-182.

${ }^{74}$ CASTILLO y RUIZ-GARCÍA (2010), p. 489. 
GÜERRI, Cristina; ALARCÓN, Pau: "Calidad de vida de migrantes presos: Diferencias en la percepción de calidad de vida penitenciaria entre migrantes y autóctonos en las prisiones españolas".

Tabla 1. Hipótesis derivadas de la revisión de la literatura y la normativa respecto a la calidad de vida en prisión

\begin{tabular}{|c|c|c|}
\hline $\begin{array}{l}\text { Calidad de } \\
\text { vida en prisión }\end{array}$ & Posibles hipótesis & Ira y normativa de referencia \\
\hline General & & CEJFE, 2010; \\
\hline Estándar de vida & $\begin{array}{l}\text { antes peor } \\
\text { ntes misma } \\
\text { ant }\end{array}$ & $\begin{array}{l}\text { Beyens y Boone, 2015; Gallego et al., 2010; Phillips, 2012; } \\
\text { Ugelvik, 2011; 2015; Ruiz-García y Castillo, 2014; } \\
\text { CM/Rec(2012)12; Departament de Justícia, 2015; } \\
\text { Rodríguez Yagüe, 2004 }\end{array}$ \\
\hline Activic & tes peor & Bhui, 2007; Mulgrew, 2018 \\
\hline $\begin{array}{l}\text { Apoy } \\
\text { reinse }\end{array}$ & $\begin{array}{l}\mathrm{H}_{\mathrm{o}} \text { : Migrantes peor } \\
\text { valoración } \\
\mathrm{H}_{\mathrm{o}} \text { : Migrantes misma } \\
\text { valoración }\end{array}$ & $\begin{array}{l}\text { Bhui, 2004a; 2004b; 2007; Warr, 2016; Beyens y Boone, } \\
\text { 2015; Montero y Durnescu, 2016; Kruttschnitt et al., } 2013 \\
\text { CM/Rec(2012)12 }\end{array}$ \\
\hline $\begin{array}{l}\text { Relaciones con } \\
\text { el personal }\end{array}$ & $\begin{array}{l}\mathrm{H}_{\mathrm{o}}: \\
\text { valo }\end{array}$ & $\begin{array}{l}\text { Phillips, 2012; Kruttschnitt et al., 2013; Montero y } \\
\text { Durnescu, 2016; Ugelvik y Damsa, 2018; Gallego et al., } \\
\text { 2010; Bhui, 2004a }\end{array}$ \\
\hline $\begin{array}{l}\text { Convi } \\
\text { entre }\end{array}$ & $\begin{array}{l}\text { antes peor } \\
\text { antes misma } \\
\text { n }\end{array}$ & $\begin{array}{l}\text { Castillo y Ruiz-García, 2010; Kruttschnitt et al., 2013; } \\
\text { Agudo, 2012 } \\
\text { Castillo y Ruiz-García, 2010; Gallego et al., 2010; CEJFE, } \\
2010\end{array}$ \\
\hline $\begin{array}{l}\text { Contacto con el } \\
\text { exterior }\end{array}$ & $\begin{array}{l}\mathrm{H}_{\mathrm{o}} \text { : Migrantes peor } \\
\text { valoración } \\
\mathrm{H}_{\mathrm{o}} \text { : Poca diferencia }\end{array}$ & $\begin{array}{l}\text { Agudo, 2014; Bhui, 2004b; 2007; } 2009 \text { Cassà, 2015; } \\
\text { Castillo y Ruiz-García, 2010; Ugelvik y Damsa, 2018; } \\
\text { Ruiz-García y Castillo, 2014; Gallego et al., } 2010 \\
\text { CM/Rec(2012)12 }\end{array}$ \\
\hline
\end{tabular}

\section{Métodos}

En la elaboración de este artículo se ha empleado la base de datos sobre calidad de vida penitenciaria confeccionada por el Grupo de Investigación en Criminología y Sistema Penal de la Universitat Pompeu Fabra mediante la administración de la adaptación al español del cuestionario MQPL (véase apartado 1.1) en cuatro centros penitenciarios de la provincia de Barcelona entre 2013 y 2016. El cuestionario fue administrado cara a cara por miembros del equipo de investigación, lo cual permitió captar también las experiencias y opiniones de quienes no saben leer o tienen dificultades con el español, además de constituir una importante fuente de información cualitativa que ha contribuido a nuestra comprensión de la vivencia del encarcelamiento.

\subsection{Muestra}

La muestra consta de 423 cuestionarios a presos varones en régimen de vida ordinario, los cuales fueron seleccionados mediante un muestreo aleatorio estratificado por módulos que recogía aproximadamente un $10 \%$ de la población de cada uno de ellos. ${ }^{75}$ De estos 423

\footnotetext{
${ }^{75}$ La población de nuestro estudio (los presos varones residentes en módulos con régimen de vida ordinario) consiste en 3.707 presos. Por lo tanto, nuestra muestra de 423 individuos representa un 11,4\% de la población.
} 
presos, 205 son nacidos en España (48,5\%) y 218 proceden de otros países $(51,5 \%)$. En la Tabla 2 se detallan los países de procedencia agrupados por regiones. Aparte de las razones geográficas, esta distinción por regiones nos permite agrupar los países recogiendo el contraste lingüístico y cultural. De este modo, los países latinoamericanos comparten el idioma y, junto a los países de Europa del Este, ciertos rasgos culturales (como la religión cristiana), mientras que los países africanos mostrarían un contraste tanto linguístico como cultural.

Tabla 2. Muestra según región y país de procedencia

\begin{tabular}{ccccc}
\hline España & Latinoamérica & África & Europa del este & Otros \\
\hline & Rep. Dominicana (16) & & Rumanía (8) & \\
& Ecuador (14) & Marruecos (70) & Georgia (4) & \\
& Colombia (9) & Senegal (6) & Serbia/Montenegro (3) & Francia (2) \\
& Cuba (9) & Nigeria (6) & Bielorrusia (2) & Italia (2) \\
& Perú (7) & Argelia (5) & Croacia (2) & Holanda (1) \\
& Chile (4) & Gambia (5) & Estonia (2) & EEUU (1) \\
España (205) & Argentina (4) & Guinea Bissau (2) & Bulgaria (2) & Pakistán (3) \\
& Bolivia (3) & Sudáfrica (2) & Bosnia (1) & Bangladesh (2) \\
& Honduras (3) & Sáhara Occidental (2) & Ucrania (1) & Palestina (1) \\
& Venezuela (2) & Túnez (2) & Rusia (1) & Iraq (1) \\
& Guatemala (2) & Costa de Marfil (1) & Hungría (1) & \\
& Brasil (1) & Mali (1) & Albania (1) & \\
\hline 205 & México (1) & & & 28 \\
\hline
\end{tabular}

La Tabla 3 muestra la comparación de la distribución de nuestra muestra según región de procedencia con el total de población penitenciaria del conjunto de las prisiones catalanas.

Tabla 3. Comparación de la región de procedencia entre la muestra y la población

\begin{tabular}{lccccc} 
& \multicolumn{2}{c}{ Muestra } & \multicolumn{2}{c}{ Población* } & Diferencia \\
\cline { 2 - 6 } & $\mathrm{N}$ & $\%$ & $\mathrm{~N}$ & $\%$ & $\%$ \\
\hline España & 205 & 48,5 & 5.127 & 56,2 & $-7,7$ \\
Latinoamérica & 75 & 17,7 & 1.278 & 14,0 & 3,7 \\
África & 102 & 24,1 & 1.629 & 17,9 & 6,3 \\
Europa del Este & 28 & 6,6 & 548 & 6,0 & 0,6 \\
Otros orígenes & 13 & 3,1 & 540 & 5,9 & $-2,8$ \\
\hline Total & 423 & 100 & 9.122 & 100 \\
*Media para los años 2013-2016 en la Administración Penitenciaria Catalana. Datos \\
extraídos del portal de Descriptors estadístics de Serveis Penitenciaris.
\end{tabular}

Para mayor detalle sobre la metodología empleada para la confección de la muestra, ver RODRÍGUEZ et al. (2018), p. 6. 


\subsection{Medidas}

A continuación, se describen los ítems de la encuesta MQPL utilizados para desarrollar el estudio. En primer lugar, se muestran la variable independiente de la investigación (el lugar de procedencia) y los controles considerados para el análisis multivariante. En segundo lugar, se presentan los diversos indicadores para medir la percepción de la calidad de vida en prisión abarcando todos los elementos identificados en el marco teórico.

\subsubsection{Variable independiente: Región de procedencia}

Dado que nuestra pregunta de investigación apunta hacia las posibles diferencias de percepción entre presos españoles y migrantes, la variable independiente hace referencia a la región de procedencia, agrupando los países en Latinoamérica, África, Europa del Este y otros orígenes. Complementariamente, en los análisis también se consideran todos los presos migrantes conjuntamente. Escogemos el país de nacimiento en vez de la nacionalidad porque queremos poner énfasis en cómo el estatus de no-nativo de las personas migrantes (falta de capital social y cultural) puede influir en su valoración de la calidad de vida en prisión. ${ }^{76}$

\subsubsection{Controles}

Para garantizar que las posibles diferencias identificadas se deben al lugar de procedencia, en el análisis multivariante se incorporan una serie de variables de control. Por ejemplo, diversas investigaciones han señalado que el perfil de los extranjeros encarcelados difiere del de los españoles presos, especialmente en lo que al consumo de drogas se refiere. ${ }^{77}$ Dado que estas diferencias en las características de los reclusos podrían influir en su valoración de los distintos indicadores de calidad de vida en prisión, al efectuar nuestros análisis controlaremos por las siguientes variables:

1) Sociodemográficas: edad.

2) Problemáticas de salud mental previas al ingreso en prisión: consumo y abuso de drogas, abuso de alcohol, comportamientos autolesivos y suicidas e internamiento en institución o módulo psiquiátrico.

3) Historial penológico: si es la primera condena del interno o es reincidente, duración de la condena y tiempo que lleva en prisión.

En la Tabla 4 se puede observar el perfil de los presos según su procedencia. En cuanto a la edad, los presos españoles y de Europa del Este tienen de media más años que los latinoamericanos y sobre todo africanos. Los españoles son claramente los que más han abusado de drogas, seguidos de los africanos. También están entre los que más han abusado del alcohol y son los que más autolesiones e intentos de suicidio han experimentado antes de entrar en prisión, han estado más internados en módulos u hospitales psiquiátricos y cuentan

\footnotetext{
${ }^{76}$ De nuestra muestra de más de 400 casos, solo 16 personas nacidas fuera de España tienen nacionalidad española (14 de distintos países de América Latina y 2 de Marruecos), con lo cual los resultados considerando la nacionalidad son prácticamente idénticos.

${ }^{77}$ GONZÁLEZ SÁNCHEZ (2012), p. 388.
} 


\section{Polít. Crim. Vol. 16, № 31 (Junio 2021), Art. 4, pp. 83-114 [http://politcrim.com/wp-content/uploads/2021/04/Vol16N31A4.pdf]}

con más reincidentes. Si bien encontramos diferentes perfiles comparando entre presos de nacionalidad española y el resto, también observamos que entre las diferentes nacionalidades no hay un perfil único sino bastante diversidad.

Tabla 4. Variables de control. Descriptivos relativos al perfil del preso según lugar de procedencia.

\begin{tabular}{|c|c|c|c|c|c|c|}
\hline & España & Latinoamérica & África & Europa del Este & Otros lugares & \multirow{2}{*}{$\mathrm{N}$} \\
\hline & $\% / \bar{x}(\mathrm{sd})$ & $\% / \bar{x}(\mathrm{sd})$ & $\% / \bar{x}(\mathrm{sd})$ & $\% / \bar{x}(\mathrm{sd})$ & $\% / \bar{x}(\mathrm{sd})$ & \\
\hline Edad (en años) & $39,5(10,7)$ & $35,8(9,8)$ & $34,6(8,1)^{*}$ & $40,2(12,2)$ & $38,4(10,7)$ & 422 \\
\hline \multicolumn{7}{|l|}{ Consumo de drogas previo al ingreso } \\
\hline No consumo de drogas & 33,5 & $67,1^{*}$ & 39,6 & $64,3 *$ & 53,8 & 418 \\
\hline Consumo de drogas (sin abuso) & 16,7 & 19,2 & $27,7 *$ & 7,1 & 23,1 & 418 \\
\hline Abuso de drogas & 49,8 & $13,7^{*}$ & $32,7 *$ & $28,6^{*}$ & 23,1 & 418 \\
\hline Abuso de alcohol anterior al ingreso en prisión & 22,1 & $9,5^{*}$ & 24,8 & 17,9 & 23,1 & 420 \\
\hline Autolesión fuera de la prisión & 12,2 & $4,1^{*}$ & 7,0 & 0,0 & 0,0 & 419 \\
\hline Intento de suicidio fuera de la prisión & 10,2 & 4,1 & 4,0 & 3,6 & 0,0 & 420 \\
\hline Internado previamente en módulo/hospital psiquiátrico & 18,5 & $1,3^{*}$ & 10,9 & 10,7 & 0,0 & 422 \\
\hline Primera vez en prisión & 40,0 & $69,3^{*}$ & 49,0 & $60,7^{*}$ & $76,9 *$ & 423 \\
\hline Duración total de la condena (en años) & $9,1(7,1)$ & $7,7(5,2)$ & $7,3(4,9)$ & $9,4(7,7)$ & $5,2(2,4)^{*}$ & 415 \\
\hline Tiempo en prisión (en años) & $3,1(3,5)$ & $1,9(2,1)^{*}$ & $2,4(2,0)$ & $2,7(3,4)$ & $1,4(0,7)^{*}$ & 422 \\
\hline
\end{tabular}

*Las diferencias (pruebas z o diferencia de medias) son estadísticamente significativas respecto a los nacidos en España a nivel 0,05

\subsubsection{Variables dependientes: Percepciones de la calidad de vida en prisión}

Dado que la calidad de vida en prisión entraña muy diversos aspectos, en este análisis se recurre a diversos ítems (variables dependientes) para abarcar los diferentes elementos identificados en el marco teórico:

1) Estándar de vida

Las condiciones de vida en esta prisión son buenas

Esta prisión está bien organizada

Se me suministra lo necesario para mantenerme limpio y aseado El personal me ayuda cuando tengo problemas médicos o de salud

No se queja de la comida

2) Actividades

No paso más de 6 horas sin actividades

Participación en actividades educativas

Tiene un puesto de trabajo (talleres o destinos)

Programa de tratamiento

3) Apoyo en la reinserción

En esta prisión me ayudan a hacer planes para no delinquir

Te explican qué tienes que hacer y te ayudan a progresar en grado

Estoy clasificado en el grado que me corresponde

Ha disfrutado de permisos

4) Relaciones con el personal (trato respetuoso)

Las relaciones son buenas

El personal me trata con respeto

Recibo apoyo del personal cuando lo necesito 
El personal me trata con amabilidad

5) Relaciones con el personal (sentirse perjudicado en la toma de decisiones)

El personal distribuye los destinos de forma justa

El personal aplica las normas de forma justa

Se respetan mis derechos como interno

6) Relaciones con otros internos (percepción de seguridad / problemas de convivencia)

En este módulo no hay muchas peleas entre internos

En esta prisión es difícil tener deudas

No siento miedo de que otros internos me golpeen insulten o amenacen

En general, no me preocupa mi seguridad física

7) Contacto con el exterior

Recibo visitas

Mantengo contacto frecuente con mi familia

En la encuesta se ha empleado una escala de Likert con 5 categorías de respuesta (desde 'muy de acuerdo' a 'muy en desacuerdo') para recoger la opinión de los presos respecto a las afirmaciones efectuadas en cada uno de los ítems ${ }^{78}$ Todas ellas han sido dicotomizadas para facilitar los análisis estadísticos y la presentación de resultados. ${ }^{79}$

\subsection{Técnicas de análisis}

Con el objetivo de comparar la percepción de la calidad de vida en prisión según la región de procedencia, utilizamos dos técnicas de análisis (bivariante y multivariante) complementarias. En primer lugar, mediante una comparación de medias, contrastamos las percepciones de los presos según los diversos ítems en función de su lugar de nacimiento. Esta primera aproximación permite identificar claramente en qué ítems los presos migrantes presentan mejores o peores valoraciones.

En segundo lugar, para corroborar que las diferencias se deben realmente al lugar de procedencia, se desarrolla un análisis multivariante mediante regresiones logísticas para cada uno de los ítems que miden la percepción de la calidad de vida en prisión. Junto al lugar de procedencia, los análisis de regresión permiten incorporar las diversas variables de control, a fin de identificar el efecto del lugar de procedencia sobre las percepciones teniendo en cuenta las diferencias sociodemográficas, las problemáticas de salud mental y el historial penológico.

Tanto las diferencias de medias como las regresiones logísticas se llevan a cabo mediante dos estrategias. Por un lado, se comparan las percepciones de los presos nacidos en España con aquellas de los nacidos en las cuatro regiones diferenciadas. Y por el otro, la comparación

\footnotetext{
${ }^{78}$ Como excepciones, la variable sobre la opinión respecto a la comida se basa en la enumeración de las tres cosas más negativas de la prisión y las variables sobre no pasar más de 6 horas sin actividades, participación en actividades educativas, programa de tratamiento y permisos son dicotómicas.

${ }^{79}$ La dicotomización ha consistido en agrupar aquellas dos categorías que implican una respuesta positiva a la dimensión que mide cada ítem, frente a las otras tres categorías (negativas o neutras). Los resultados de los análisis son robustos y no cambian sensiblemente al utilizar criterios alternativos para dicotomizar las variables (para mayor detalle, véase RODRÍGUEZ et al. (2018), pp. 3-4.
} 


\section{Polít. Crim. Vol. 16, № 31 (Junio 2021), Art. 4, pp. 83-114 \\ [http://politcrim.com/wp-content/uploads/2021/04/Vol16N31A4.pdf]}

se realiza considerando a todos los presos nacidos fuera de España conjuntamente. Este diseño metodológico permite observar si el colectivo de presos migrantes presenta opiniones homogéneas o si, en cambio, existen percepciones diferenciadas según la región de procedencia.

A lo largo del estudio, los resultados cuantitativos se apoyan en la información cualitativa recabada durante las entrevistas, utilizada a modo ilustrativo.

\section{Resultados}

En primer lugar, la Tabla 5 muestra los resultados de la comparación de medias. Al tratarse de variables dicotómicas, los datos pueden interpretarse como el porcentaje de presos que percibe de forma positiva cada uno de los ítems sobre la calidad de vida en prisión (mientras que los restantes las perciben de forma negativa o neutra). Así, por ejemplo, el $33 \%$ de los presos españoles consideran que las condiciones de vida son buenas, en comparación con el $42 \%$ de los presos nacidos fuera de España.

En general, las percepciones sobre la calidad de vida en prisión son bastante negativas. El porcentaje de presos nacidos en España que se muestran satisfechos es superior al 50\% solamente en 12 de los 26 ítems. En el caso de los migrantes sucede en 18 ítems, mostrando un nivel de satisfacción algo mayor. En términos generales, el contacto con el exterior y las relaciones con el personal en cuanto a diferencias de trato con otros presos cuentan con valoraciones más positivas. En cambio, el apoyo a la reinserción está asociado a percepciones más negativas.

Comparativamente, los presos migrantes muestran percepciones más positivas que los españoles en cuanto al estándar de vida en prisión, las relaciones con el personal y la realización de actividades (con la excepción de los programas de tratamiento). La percepción con relación al apoyo recibido para la reinserción, las relaciones con otros internos y el contacto con el exterior dependen de los ítems concretos, mostrando valoraciones más positivas o negativas que los españoles (por ejemplo, los presos nacidos fuera de España sienten, en comparación, más preocupación por su seguridad física, pero al mismo tiempo perciben que se producen menos peleas en su módulo).

Si bien las percepciones de los presos migrantes suelen diferir de las de los españoles en un mismo sentido, también podemos observar que no se trata de un colectivo sólidamente homogéneo, existiendo diferentes grados de satisfacción según la región de procedencia. En este sentido, los presos de procedencia latinoamericana y de otros lugares son los que muestran percepciones más positivas en comparación con los de origen africano y de Europa del Este (por ejemplo, en la percepción de que las condiciones de vida en prisión son buenas).

No obstante, hay que tomar estos hallazgos con cierta cautela, dado que solo aparecen diferencias estadísticamente significativas en 16 de los 27 ítems analizados. En algunos casos, las diferencias entre presos españoles y el resto son significativas, pero el contraste se debe solamente a diferencias entre españoles y aquellos nacidos en una región específica 
(como por ejemplo, en el caso de los presos latinoamericanos y su mayor contacto con la familia, o la mayor preocupación por la seguridad física de los presos africanos).

Tabla 5. Comparación de medias de las percepciones sobre calidad de vida en prisión según lugar de procedencia

\begin{tabular}{|c|c|c|c|c|c|c|c|}
\hline & España & Latinoamérica & África & $\begin{array}{l}\text { Europa } \\
\text { del Este }\end{array}$ & $\begin{array}{c}\text { Otros } \\
\text { lugares }\end{array}$ & $\begin{array}{l}\text { Nac. fuera } \\
\text { de España }\end{array}$ & $\mathbf{N}$ \\
\hline \multicolumn{8}{|l|}{ Estándar de vida } \\
\hline Condiciones de vida son buenas & 0,33 & $0,55^{* *}$ & 0,33 & 0,32 & 0,62 & $0,42 * *$ & 414 \\
\hline Prisión bien organizada & 0,33 & $0,57 * * *$ & $0,58 * * *$ & 0,46 & 0,62 & $0,56^{* * *}$ & 413 \\
\hline Necesario para mantenerse limpio & 0,38 & $0,57 *$ & 0,51 & 0,61 & $0,77 *$ & $0,56 * * *$ & 419 \\
\hline Ayuda con problemas médicos & 0,61 & 0,64 & 0,64 & 0,76 & $0,92 * *$ & 0,67 & 406 \\
\hline No se queja de la comida & 0,57 & 0,67 & 0,66 & 0,64 & 0,69 & $0,66^{* *}$ & 423 \\
\hline \multicolumn{8}{|l|}{ Actividades } \\
\hline No pasa más de $6 \mathrm{hs}$ sin actividades & 0,52 & $0,75^{* * *}$ & 0,63 & $0,79 * *$ & 0,62 & $0,69 * * *$ & 423 \\
\hline Participa en actividades educativas & 0,29 & 0,29 & 0,38 & 0,29 & 0,46 & 0,34 & 423 \\
\hline Tiene puesto de trabajo (talleres/destinos) & 0,42 & 0,59 & 0,54 & 0,61 & 0,62 & $0,57 * * *$ & 423 \\
\hline Programa de tratamiento & 0,61 & 0,68 & 0,49 & 0,39 & 0,46 & 0,54 & 421 \\
\hline \multicolumn{8}{|l|}{ Apoyo a la reinserción } \\
\hline Ayudan a hacer planes para no delinquir & 0,38 & 0,46 & 0,49 & 0,36 & 0,54 & $0,47 *$ & 418 \\
\hline Explican qué hacer para progresar en grado & 0,44 & 0,48 & 0,54 & 0,5 & 0,54 & 0,51 & 421 \\
\hline Clasificado en grado que corresponde & 0,21 & 0,29 & 0,15 & 0,15 & 0,15 & 0,2 & 410 \\
\hline Ha disfrutado de permisos & 0,36 & $0,16^{* *}$ & 0,2 & $0,08 * *$ & $0,00 * * *$ & $0,15^{* * *}$ & 233 \\
\hline \multicolumn{8}{|l|}{ Relac. con el personal (diferencias de trato) } \\
\hline Las relaciones con personal son buenas & 0,52 & 0,6 & 0,59 & 0,68 & $0,85^{*}$ & $0,62 * *$ & 422 \\
\hline Recibe trato respetuoso & 0,87 & 0,86 & 0,79 & 0,89 & 0,67 & 0,82 & 119 \\
\hline Recibe apoyo del personal si lo necesita & 0,49 & 0,57 & 0,54 & 0,54 & 0,69 & 0,56 & 421 \\
\hline Recibe trato con amabilidad & 0,6 & 0,55 & 0,68 & 0,54 & 0,62 & 0,61 & 414 \\
\hline \multicolumn{8}{|l|}{ Relac. con el personal (diferencias decisorias) } \\
\hline Destinos distribuidos de forma justa & 0,31 & 0,44 & 0,46 & 0,5 & $0,75^{*}$ & $0,48 * * *$ & 412 \\
\hline Normas aplicadas de forma justa & 0,31 & 0,47 & $0,59 * * *$ & 0,5 & 0,62 & $0,54 * * *$ & 419 \\
\hline Respeto de derechos como interno & 0,42 & 0,47 & 0,49 & 0,61 & 0,54 & $0,50 *$ & 414 \\
\hline \multicolumn{8}{|l|}{ Relaciones con otros internos } \\
\hline No hay muchas peleas en módulo & 0,62 & $0,78^{*}$ & 0,64 & 0,57 & $0,92 * *$ & $0,69 *$ & 419 \\
\hline Es difícil tener deudas & 0,31 & 0,38 & 0,26 & 0,42 & 0,42 & 0,33 & 406 \\
\hline Sin miedo de ser golpeado o amenazado & 0,78 & 0,89 & 0,79 & 0,82 & 0,92 & 0,84 & 421 \\
\hline No preocupa seguridad física & 0,59 & 0,58 & $0,36^{* *}$ & 0,47 & 0,7 & $0,48^{*}$ & 300 \\
\hline \multicolumn{8}{|l|}{ Contacto con el exterior } \\
\hline Puede recibir visitas con frecuencia & 0,75 & 0,71 & 0,67 & 0,68 & 0,69 & 0,69 & 394 \\
\hline Tiene contacto frecuente con familia & 0,86 & $0,97 * * *$ & 0,85 & 0,82 & 0,85 & 0,89 & 423 \\
\hline
\end{tabular}

*** La diferencia de medias con los presos nacidos en España es estadísticamente significativa a nivel 0,01; ** 0,05; * 0,1.

Las diferencias anteriores se basan en un análisis bivariado, útil para una aproximación inicial pero que requiere de un análisis multivariante para comprobar que el lugar de origen realmente explica la diversidad de opiniones entre los presos una vez que controlamos por diversas variables. De esta forma, la Tabla 6 resume los resultados de los análisis de regresión logística, mostrando únicamente los efectos del lugar de procedencia (haber nacido en España se mantiene como categoría de referencia para facilitar la comparación con los demás presos). 
El signo de estos coeficientes de las regresiones y la Tabla 5 anterior son prácticamente idénticos. Es decir, si el análisis bivariado mostraba que las percepciones de los presos con un determinado origen son más positivas o negativas que las de los españoles, una vez que se controla por las diversas variables del análisis de regresión, esa diferencia de percepciones apunta en la misma dirección. Asimismo, los efectos del lugar de procedencia sobre las percepciones de la calidad de vida en prisión son estadísticamente significativos en prácticamente los mismos ítems que mostraba la comparación de medias anterior. Por tanto, las diferencias comentadas anteriormente se sostienen de forma rigurosa en términos generales.

En cuanto a las diferencias considerando las regiones de origen, se observan perfiles diferenciados. Los presos de origen latinoamericano muestran los mayores niveles de satisfacción con la calidad de vida en prisión. En cambio, los de origen africano son los que muestran valoraciones negativas en mayor cantidad de ítems. Los presos de Europa del Este, por su parte, se encuentran en una posición intermedia, siendo los que muestran menos opiniones tanto positivas como negativas en comparación con los españoles. 
Tabla 6. Resumen del análisis de regresión logística: Coeficientes $B$ de las percepciones sobre calidad de vida en prisión según lugar de procedencia (categoría de referencia: nacionalidad española)

\begin{tabular}{|c|c|c|c|c|c|c|c|c|}
\hline & $\begin{array}{l}\text { Latino- } \\
\text { américa } \\
\text { Coef. B }\end{array}$ & $\begin{array}{l}\text { África } \\
\text { Coef. B }\end{array}$ & $\begin{array}{l}\text { Europa } \\
\text { del Este } \\
\text { Coef. B }\end{array}$ & $\begin{array}{c}\text { Otros } \\
\text { Coef. B }\end{array}$ & $\begin{array}{c}\mathrm{R} 2 \\
\text { Nagel- } \\
\text { kerke }\end{array}$ & $\begin{array}{c}\text { Nac. } \\
\text { fuera de } \\
\text { España. } \\
\text { Coef. B }\end{array}$ & $\begin{array}{l}\text { R2 } \\
\text { Nagel- } \\
\text { kerke }\end{array}$ & $\mathrm{N}$ \\
\hline \multicolumn{9}{|l|}{ Estándar de vida } \\
\hline Condiciones de vida son buenas & $\mathbf{0 , 7 5 * *}$ & 0,025 & $-0,229$ & 0,876 & 0,125 & 0,257 & 0,103 & 396 \\
\hline Prisión bien organizada & $0,660 * *$ & $1,210 * * *$ & 0,139 & $1,096 *$ & 0,203 & $0.856 * * *$ & 0,186 & 396 \\
\hline Necesario para mantenerse limpio & $0,677 * *$ & $0,502 *$ & $\mathbf{0 , 7 4 0 *}$ & $1,402 * *$ & 0,091 & $0.633 * * *$ & 0,085 & 401 \\
\hline Ayuda con problemas médicos & 0,220 & 0,268 & 0,612 & $2,080 *$ & 0,088 & 0,364 & 0,072 & 389 \\
\hline No se queja de la comida & 0,265 & 0,410 & 0,113 & 0,428 & 0,086 & 0,322 & 0,084 & 405 \\
\hline \multicolumn{9}{|l|}{ Actividades } \\
\hline No pasa más de $6 \mathrm{hs}$ sin actividades & $\mathbf{0 , 7 0 3} * *$ & 0,385 & $0,947 *$ & 0,295 & 0,128 & $0.548 * *$ & 0,122 & 405 \\
\hline Participa en actividades educativas & $-0,128$ & 0,361 & $-0,115$ & 0,869 & 0,048 & 0,184 & 0,035 & 405 \\
\hline Tiene puesto de trabajo (talleres/destinos) & 0,426 & 0,296 & 0,673 & 0,818 & 0,095 & $0.417 *$ & 0,091 & 405 \\
\hline Programa de tratamiento & $\mathbf{0 , 5 4 5 *}$ & $-\mathbf{0 , 5 0 4 *}$ & $-0,752 *$ & $-0,331$ & 0,072 & $-0,233$ & 0,033 & 403 \\
\hline \multicolumn{9}{|l|}{ Apoyo a la reinserción } \\
\hline Ayudan a hacer planes para no delinquir & 0,414 & $0,507 *$ & $-0,203$ & 0,437 & 0,041 & $0.370^{*}$ & 0,033 & 401 \\
\hline Explican qué hacer para progresar en grado & 0,161 & 0,411 & 0,091 & 0,490 & 0,053 & 0,293 & 0,049 & 403 \\
\hline Clasificado en grado que corresponde & $\mathbf{0 , 7 1 8 *}$ & $-0,255$ & $-0,404$ & $-0,013$ & 0,134 & 0,071 & 0,109 & 397 \\
\hline Ha disfrutado de permisos & $-0,688$ & $-0,652$ & $-2,073 *$ & $-20,18$ & 0,238 & $-0.936 * *$ & 0,213 & 223 \\
\hline \multicolumn{9}{|l|}{ Relac. con el personal (diferencias de trato) } \\
\hline Las relaciones con personal son buenas & 0,280 & 0,424 & 0,432 & $1,370 *$ & 0,170 & $0.418^{*}$ & 0,165 & 404 \\
\hline Recibe trato respetuoso & 0,360 & $-0,122$ & 0,538 & 19,849 & 0,123 & 0,130 & 0,104 & 117 \\
\hline Recibe apoyo del personal si lo necesita & 0,319 & 0,351 & $-0,077$ & 0,748 & 0,083 & 0,297 & 0,078 & 403 \\
\hline $\begin{array}{l}\text { Recibe trato con amabilidad } \\
\text { Relaciones con el personal (diferencias } \\
\text { decisorias) }\end{array}$ & $-0,510$ & 0,438 & $-0,474$ & $-0,392$ & 0,125 & $-0,026$ & 0,097 & 396 \\
\hline Destinos distribuidos de forma justa & 0,316 & $0,746 * * *$ & $\mathbf{0 , 7 6 0 *}$ & $1,587 * *$ & 0,117 & $0.659 * * *$ & 0,105 & 394 \\
\hline Normas aplicadas de forma justa & 0,458 & $1,365 * * *$ & 0,468 & 0,823 & 0,182 & $0.915 * * *$ & 0,158 & 401 \\
\hline Respeto de derechos como interno & 0,269 & $0,492 *$ & $\mathbf{0 , 7 5 4} *$ & 0,095 & 0,109 & $0.442 *$ & 0,104 & 396 \\
\hline \multicolumn{9}{|l|}{ Relaciones con otros internos } \\
\hline No hay muchas peleas en módulo & $\mathbf{0 , 8 2 3} * *$ & 0,154 & $-0,173$ & $1,856 *$ & 0,093 & 0,329 & 0,067 & 402 \\
\hline Es difícil tener deudas & 0,192 & $-0,269$ & 0,446 & 0,307 & 0,065 & 0,022 & 0,055 & 389 \\
\hline Sin miedo de ser golpeado o amenazado & $\mathbf{0 , 7 6 5 *}$ & 0,152 & 0,504 & 1,189 & 0,056 & 0,417 & 0,047 & 403 \\
\hline No preocupa seguridad física & $-0,033$ & $1,038 * * *$ & $-0,430$ & 0,290 & 0,098 & $-0,527 *$ & 0,067 & 284 \\
\hline \multicolumn{9}{|l|}{ Contacto con el exterior } \\
\hline Puede recibir visitas con frecuencia & $-0,346$ & $-0,545 *$ & $-0,488$ & $-0,401$ & 0,065 & $-0,475^{*}$ & 0,064 & 377 \\
\hline Tiene contacto frecuente con familia & 1,652 & $-0,614$ & $-0,814$ & $-1,025$ & 0,206 & $-0,360$ & 0,166 & 405 \\
\hline
\end{tabular}

*** El lugar de nacimiento tiene un efecto estadísticamente significativo sobre la percepción a nivel 0,01 ; $* * 0{ }^{\prime} 05 ; * 0 ' 1$.

Variables de control incluidas en los análisis: edad, consumo de drogas, problemas con abuso de drogas, problemas con abuso de alcohol, autolesión, intento de suicidio, ingreso en módulo/hospital psiquiátrico, primera vez en prisión, duración total de la condena, tiempo en prisión. 
La tabla anterior no muestra los efectos de las variables de control por razones de espacio. La edad del preso es un factor explicativo en muchos casos: cuantos más años se tiene, mejor percepción de la calidad de vida en prisión hay. También son recurrentemente relevantes el consumo y los problemas con abuso de drogas, con un efecto negativo en esos niveles de satisfacción, así como el tiempo que el preso lleva en prisión, con un efecto variable según los ítems (positivo en relación con los permisos, puestos de trabajo, programas de tratamiento o la recepción de explicaciones para progresar de grado pero negativo en otras cuestiones). Asimismo, en algunos casos los internos primarios muestran niveles de satisfacción más elevados, mientras que el haber estado internado en un módulo u hospital psiquiátrico, haber abusado del alcohol o sufrido autolesiones o intentos de suicidio tiene en ocasiones un efecto negativo en los niveles de satisfacción. Para mayor detalle, véase el Anexo I.

\section{Discusión}

Se confirma la hipótesis de que los migrantes presos en los centros penitenciarios catalanes manifiestan una valoración más positiva de sus condiciones de vida en prisión que los autóctonos. Esto puede deberse a lo que algunos autores que estudian la percepción de legitimidad que la ciudadanía tiene de la policía en España han denominado "efecto amortiguador", ${ }^{80}$ y que implicaría que los grupos de población con experiencias personales o contextos culturales donde las prisiones sean mucho peores que las de España concederán mejor valoración a las prisiones españolas por el contraste, independientemente de la calidad objetiva del encierro. La información cualitativa recabada durante la realización de las entrevistas contribuye a reforzar esta explicación. Por ejemplo, un preso ecuatoriano del CP3 señalaba "No le voy a decir nada malo de esta prisión porque yo he visto cómo son las cárceles en Ecuador", o un preso rumano del CP4 decía "Esto no es cárcel: cárcel era lo de Rumanía durante el comunismo".

En lo relativo a aspectos concretos del estándar de vida, la valoración de la higiene, la atención médica o la alimentación no presentan grandes diferencias entre autóctonos e inmigrantes, por lo que las quejas de poca frecuencia de la atención médica detectadas en otros estudios ${ }^{81}$ pueden achacarse a un déficit general de la prisión y no a una peor atención hacia los foráneos. Es decir, si bien los niveles de satisfacción de todos los presos con los aspectos recogidos en estos ítems no son óptimos, se constata que, como mínimo, no hay una situación de discriminación hacia los migrantes.

La recomendación europea relativa al igual acceso de los presos de terceros países a un programa equilibrado de actividades parece cumplirse en las prisiones catalanas. Una proporción mayor de latinoamericanos y europeos del Este manifiestan una elevada

\footnotetext{
${ }^{80}$ En su investigación sobre la percepción de legitimidad que la ciudadanía tiene de la policía en España, GARCÍA-AÑÓN et al. (2013), p. 32, observan que las personas que pertenecen a comunidades minoritarias y migrantes tienden a confiar más y a conceder más legitimidad a la policía que la población mayoritaria, cuestión que atribuyen a que estos grupos de población tienen experiencias personales o proceden de contextos culturales en los que la policía es mucho peor en términos de justicia y efectividad. Por ello, concluyen que la policía española se está beneficiando de un "efecto amortiguador" en lo que respecta a las opiniones de los grupos minoritarios.

${ }^{81}$ Por ejemplo, RUIZ-GARCÍA y CASTILLO (2014), p. 595.
} 
ocupación del tiempo y no hay diferencias significativas en la participación en actividades educativas o trabajo remunerado. No obstante, sí que se evidencian diferencias en la participación en programas de tratamiento, inferior en africanos y europeos del Este. El hecho de que sean estos dos grupos pero no los latinoamericanos quienes participan en menor medida sugiere que podría estar operando una barrera idiomática. ${ }^{82}$ En este sentido, algunos presos entrevistados manifiestan no querer participar en programas porque "te hacen explicar cosas de ti y a veces no me salen las palabras, no estaría cómodo" (palestino de Gaza, CP4). Otra posible explicación es que muchos presos realizan estos programas con una finalidad instrumental para acceder a permisos penitenciarios ${ }^{83}$ y saber que por su condición de extranjeros no podrán obtenerlos puede estar desincentivando su participación.

Respecto a la ayuda a la reinserción, los datos no sustentan en el caso de las prisiones catalanas la tesis de que los inmigrantes reciben menor apoyo por su peor pronóstico de reinserción. ${ }^{84}$ De hecho, las únicas diferencias significativas muestran una valoración positiva de los africanos del apoyo que reciben para hacer planes de futuro y menos latinoamericanos se sienten injustamente clasificados en segundo grado. Sí se evidencia, no obstante, la menor concesión de permisos ${ }^{85}$ y los efectos negativos que tiene sobre los presos, privación de legitimidad y privación de esperanza, ${ }^{86}$ sufrimientos de la discriminación: ${ }^{87}$

"Me dicen que no puedo salir de permiso por riesgo de fuga... después de quince años viviendo en España, ¿creen voy a ir a algún lado? Los españoles salen mucho más porque son de aquí y eso desanima. Es discriminación." (Costa de Marfil, CP1)

"No poder salir, saber que haga lo que haga no voy a conseguir permisos... me ha quitado las ganas de participar y de hacer el papel del buen preso. Que me dejen en paz, que pasen los años y que me suelten, pero que no me vengan a explicar que tal cursillo te va a ir muy bien o que tal otro te va a ayudar cuando salgas." (Sahara Occidental, CP1)

Tampoco hay diferencias significativas en la precepción de trato por parte del personal: las valoraciones sobre la calidad de las relaciones entre internos y personal, el trato respetuoso y amable o el apoyo recibido cuando se ha necesitado no difieren entre autóctonos y migrantes. La investigación sobre calidad de vida en prisión ha mostrado que los internos no tienen una opinión global sobre el conjunto de los funcionarios, sino que consideran que los hay mejores y peores. ${ }^{88}$ Esta valoración matizada del personal parece trasladarse a la interpretación del trato de los funcionarios a los internos no nacidos en España: "Los funcionarios en general son buenos y te hablan con educación, aunque también los hay malos que sólo te dan órdenes de mala manera. También hay funcionarios racistas que te buscan y te tratan mal aunque no hagas nada" (Tanzania, CP4). Es decir, aunque los internos puedan

\footnotetext{
${ }^{82}$ DE MARCOS (2010), p.3, señala que la dificultad idiomática es uno de los principales problemas que la administración penitenciaria encuentra a la hora de abordar el tratamiento de los extranjeros presos. También GARCÍA-ESPAÑA (2007), pp. 118-120.

${ }^{83}$ LARRAURI et al. (2017), p. 5.

${ }^{84}$ BHUI (2004b), pp. 36-37; MULGREW (2018), pp. 80-81.

${ }^{85}$ Ya señalada por ROVIRA et al. (2018), pp. 14-15, e IBÀÑEZ (2019), p. 22.

${ }^{86}$ WARR (2016), pp. 310-314.

${ }^{87}$ UGELVIK y DAMSA (2018), pp. 1029-1032.

${ }^{88}$ Por ejemplo, RÍOS y CABRERA (1998), p. 42.
} 


\section{Polít. Crim. Vol. 16, № 31 (Junio 2021), Art. 4, pp. 83-114 [http://politcrim.com/wp-content/uploads/2021/04/Vol16N31A4.pdf]}

percibir un trato racista por algún funcionario (experiencia que, por desgracia, no distará de lo vivido en el exterior), la percepción generalizada respecto al conjunto del personal es que el trato es adecuado. ${ }^{89}$

Sí hay más diferencias respecto a la forma de aplicación de las normas pero, contrariamente a lo que apuntaban Montero y Durnescu, ${ }^{90}$ los migrantes tienden a hacer una mejor valoración. Los españoles son especialmente críticos con la asignación de destinos, lo cual concuerda con nuestros datos: los migrantes acceden a destinos en mayor medida que los nacionales. Esto puede explicarse tanto por los criterios de asignación de destinos (se priorizan aquellos sin recursos - porque por ejemplo la familia no se los puede enviar- y con cargas familiares) como por la mayor formación de la población extranjera, que facilita el acceso a ciertos puestos de trabajo. ${ }^{91}$

Finalmente, encontramos una percepción negativa del contacto con el exterior de los presos africanos y europeos del Este. Esta diferencia con los autóctonos y latinoamericanos está claramente relacionada con el perfil de migrante económico alejado de su entorno familiar y social, pues cuando controlamos las respuestas relativas a recibir visitas con el ítem "Esta prisión está cerca de mi casa" estas diferencias desaparecen. ${ }^{92}$ Por tanto, estos dos grupos de presos están en una situación de mayor aislamiento ( $\mathrm{y}$, posiblemente, menor acceso a recursos) fruto de su proceso migratorio y es importante que la recomendación 26.2 de la $\operatorname{Rec}(2012) 2$ respecto a favorecer el desarrollo de las relaciones de los reclusos con el mundo exterior mediante organizaciones comunitarias y voluntarias sea especialmente tenida en cuenta.

En comparación con los presos españoles, los migrantes muestran niveles de satisfacción que, generalmente, apuntan en la misma dirección. Sin embargo, el colectivo de presos migrantes también muestra algunas diferencias internas destacables. Así, hemos visto que los de origen africano están comparativamente menos satisfechos con los contactos con el exterior, probablemente al tratarse de perfiles migratorios más aislados físicamente de su entorno familiar y social. También valoran más negativamente las relaciones de trato con el personal y los otros internos, reflejando la brecha linguística en comparación con los presos latinoamericanos o la mayor brecha cultural respecto a los presos de Europa del Este. En contraste, los de origen latinoamericano son quienes muestran percepciones más positivas de la calidad de vida en prisión, quizá debido a la importancia de compartir el mismo idioma. ${ }^{93}$

\footnotetext{
${ }^{89}$ En la evidencia cualitativa sí se aprecia un sentir general por parte de internos magrebíes respecto a ser peor tratados por el personal (“A los extranjeros se nos trata peor, con menos respeto". Marruecos, CP4), algo que reflejan nuestros datos pero sin llegar a ofrecer diferencias estadísticamente significativas. Estos resultados son similares a lo observado por KRUTTSCHNITT et al. (2013), pp. 489-490, en Inglaterra.

${ }^{90}$ MONTERO y DURNESCU (2016), p. 37.

${ }^{91}$ CASTILLO y RUIZ-GARCÍA (2010), p. 486.

${ }^{92}$ El contacto con la familia depende de la cercanía del hogar. Así, un 93,0\% de los presos españoles reciben visitas cuando la prisión está cerca de casa, mientras que el porcentaje baja al 71,6\% en caso contrario. Todos los presos nacidos en Latinoamérica reciben visitas cuando la prisión está cerca de casa (frente al 68,9\% en caso contrario), mientras los porcentajes son del $97,8 \%$ y del $51,8 \%$ respectivamente para los africanos, del $66,7 \%$ y $42,9 \%$ para los de Europa del Este, y del $100 \%$ y $50 \%$ para el resto de los orígenes. Para España, Latinoamérica y África las diferencias de visitas según la cercanía de la casa son estadísticamente significativas a nivel 0,05 .

${ }^{93}$ Cuestión que ya había sido apuntada por SALES (2018), p. 143.
} 
GÜERRI, Cristina; ALARCÓN, Pau: "Calidad de vida de migrantes presos: Diferencias en la percepción de calidad de vida penitenciaria entre migrantes y autóctonos en las prisiones españolas".

Todo ello enfatiza la importancia de que las investigaciones empíricas diferencien entre colectivos de inmigrantes (o extranjeros) siempre que sea posible, en lugar de considerarlos un colectivo homogéneo.

Por último, debemos mencionar que las diferentes percepciones de la calidad de vida en prisión según el lugar de procedencia generalmente se mantienen cuando controlamos por otras explicaciones relevantes, destacando un factor sociodemográfico como es la edad, además de problemáticas de salud mental previas al ingreso en prisión o el historial penológico del preso.

\section{Conclusiones}

La sobrerrepresentación de migrantes en las prisiones de Europa occidental ha generado una creciente preocupación por conocer la situación de los presos extranjeros en las cárceles europeas y garantizar que se cumplen los principios establecidos por la Recomendación $\mathrm{CM} / \operatorname{Rec}(2012) 12$ relativa a los presos extranjeros. Sin embargo, la literatura sobre esta cuestión en España es escasa y no permite discernir qué problemáticas son comunes a nacionales y extranjeros y cuáles son específicas de los segundos. Por ello, nuestro objetivo ha sido comprobar si la vivencia en las cárceles catalanas difiere entre presos autóctonos y migrantes mediante el análisis comparativo de sus respuestas al cuestionario MQPL sobre calidad de vida en prisión.

Una primera conclusión es que, en términos generales, la valoración de los migrantes de su calidad de vida en prisión no es peor que la de los nacionales. En concreto, su percepción del estándar de vida en prisión, de su ocupación del tiempo y del apoyo y trato recibido por parte del personal es similar a la de los españoles, e incluso mejor en cuestiones como la organización de la prisión o la aplicación de las normas. Esto parece sugerir que la administración penitenciaria realiza un buen trabajo a la hora de proporcionar la igualdad de trato prescrita en la legislación.

No obstante, el hecho de que no sea peor no significa que sea buena. Por ejemplo, hemos señalado que no hay diferencias en la percepción de apoyo por parte del personal, pero solo un $49 \%$ de presos españoles y un $56 \%$ de extranjeros afirma recibirlo, lo cual deja fuera a alrededor de la mitad de los encuestados. En otras palabras, constatamos que no existe una vivencia subjetiva del encarcelamiento diferenciada que sugiera una discriminación en el trato, no que la calidad de vida sea objetivamente buena.

Una segunda cuestión es qué aspectos concretos sí presentan una valoración más negativa por parte de los presos migrantes. En este sentido, constatamos una menor participación en programas de tratamiento, probablemente debida a la falta de dominio del idioma, y un mayor desarraigo en los casos de presos africanos y europeos del Este, ambas cuestiones asociadas con sus trayectorias vitales. Estos elementos repercuten, a su vez, en un peor pronóstico de reinserción y el consecuente menor acceso a los mecanismos de progresión penitenciaria (permisos y tercer grado) que también hemos observado en nuestros datos. Dicha situación se ve agravada por la condición de 'expulsables' de aquellos extranjeros que han cometido 


\section{Polít. Crim. Vol. 16, № 31 (Junio 2021), Art. 4, pp. 83-114 [http://politcrim.com/wp-content/uploads/2021/04/Vol16N31A4.pdf]}

un delito. ${ }^{94}$ Es decir, si bien la calidad de vida en prisión no es peor para los presos migrantes, sí advertimos la discriminación estructural, previamente señalada por otros autores, que les impide progresar hacia la libertad en las mismas condiciones que lo hacen los presos españoles. ${ }^{95}$

Por último, cabe destacar las diferencias observadas en las percepciones de la calidad de vida en función de la región de procedencia. Así, los presos de origen africano o de Europa del Este tienden a mostrar valoraciones más negativas en algunos aspectos, mientras que los latinoamericanos son más positivos en otros. Esto demuestra la importancia de no tratar a los inmigrantes como un colectivo homogéneo incluso si, como bien señala Bhui, ${ }^{96}$ pueden experimentar dificultades similares derivadas del proceso migratorio y del estatus de no nativos. Concluimos, por tanto, enfatizando la necesidad de contemplar estas diferencias en el diseño e implementación de las políticas penitenciarias, así como la importancia de que futuras investigaciones incorporen esta distinción para contribuir a una mejor comprensión de cómo el lugar de procedencia influye en la percepción de calidad de vida en prisión.

\footnotetext{
${ }^{94}$ La legislación española de extranjería que convierte a aquellos extranjeros que han cometido un delito doloso penado con más de 1 año de prisión en 'expulsables', dificultando todavía más su acceso a los referidos mecanismos de reinserción. GARCÍA-ESPAÑA (2018b), pp. 137-139, ALMEIDA y CARRETERO (2019), pp. $98-100$.

95 A estos efectos, es necesario tener presente que las dos administraciones penitenciarias españolas han desarrollado recientemente normativas que diseñan distintos itinerarios de tratamiento en función del perfil del migrante y las posibilidades de reinserción que les permite la ley de extranjería para tratar de paliar estas situaciones de discriminación y evitar que aquellos migrantes con arraigo y proyecto de vida en España se vean excluidos de los mecanismos de reinserción. Para mayor detalle, véanse la Instrucción 3/2019, sobre internos extranjeros, de la Secretaría General de Instituciones Penitenciarias y la Circular 2/2019, sobre estrangeria als centres penitenciaris de Catalunya, de la Secretaria de Mesures Penals i Atenció a la Víctima.

${ }^{96}$ BHUI (2009), p. 166.
} 
GÜERRI, Cristina; ALARCÓN, Pau: “Calidad de vida de migrantes presos: Diferencias en

\section{Bibliografía citada}

AEBI, Marcelo F.; BERGER-KOLOPP, Léa; BURKHARDT, Christine; CHOPIN, Julien; HASHIMOTO; Yuji Z. y TIAGO, Mélanie M. (2019): Foreign offenders in prison and on probation in Europe - Trends from 2005 to 2015 (inmates) and situation in 2015 (inmates and probationers), (Strasbourg, Council of Europe), Vol. 1.

AEBI, Marcelo F.; TIAGO, Mélanie M. (2020): SPACE I - 2019. Council of Europe Annual Penal Statistics: Prison populations (Strasbourg: Council of Europe).

AGUDO, Yolanda (2012): "Desigualdades implícitas y sentidas por mujeres extranjeras en centros penitenciarios españoles”, en: GARCÍA DE CORTÀZAR, María Luisa (Coord.), Estudio sobre discriminación en el ámbito penitenciario: Extranjeras en las prisiones españolas (Instituto de la Mujer y para la Igualdad de Oportunidades, Madrid), pp. 79-112.

ALMEIDA, Cristina; CARRETERO, Miryam (2019): "Extranjeros en prisión. El papel de la expulsión", en: Revista Crítica Penal y Poder ( $\left.\mathrm{N}^{\circ} 18\right)$, pp. 94-102.

BARQUÍN, Jesús; CANO, Miguel Ángel; CALVO, María Ángeles (2016): "Percepción de la calidad de vida en prisión por los reclusos en dos centros. Una aproximación en materia de reinserción", en: MORILLAS, Lorenzo (Ed.), La pena de prisión entre el expansionismo y el reduccionismo punitivo (Madrid, Dykinson), pp. 459-511.

BARQUÍN, Jesús; CANO, Miguel Ángel; CALVO, María Ángeles (2019): "Treatment, Reintegration, and Quality of Prison Life: Perception by Inmates", en: International Journal of Offender Therapy and Comparative Criminology (Vol. 63, Núm.13), pp. 2291-2317.

BEYENS, Kristel; BOONE, Miranda (2015): "Mixing detention cultures: the Belgian Dutch case", en: DRAKE, Deborah H.; EARLE, Rod; SLOAN, Jennifer (Eds.): The Palgrave Handbook of Prison Ethnography (Palgrave Macmillan), pp. 479498.

BHUI, Hindpal S. (2004a): Going the distance: Developing effective policy and practice with foreign national prisoners. Research report (London, Prison Reform Trust).

BHUI, Hindpal S. (2004b): "The resettlement needs of foreign national offenders", en: Criminal Justice Matters (Vol. 56, Núm. 1), pp. 36-44.

BHUI, Hindpal S. (2007): "Alien experience: Foreign national prisoners after the deportation crisis", en: Probation Journal (54.4), pp. 368-382.

BHUI, Hindpal S. (2009): "Foreign national prisoners: issues and debates", en: BHUI, Hindpal S. (Ed.), Race and Criminal Justice (London, SAGE), pp. 154-169.

BRANDARIZ, José Ángel (2011): Sistema penal y control de los migrantes: Gramática del migrante como infractor penal (Granada, Comares).

BRANDARIZ, José Ángel; FERNÁNDEZ-BESSA, Cristina (2010): “La construcción de los migrantes como categoría de riesgo: fundamento, funcionalidad y consecuencias para el sistema penal español”, en: PALIDDA, Salvatore; BRANDARIZ, José Ángel (Dir.), Criminalización racista de los migrantes en Europa(Granada, Comares), pp. 271-289.

BRANDARIZ, José Ángel; FERNÁNDEZ-BESSA, Cristina (2017): “La crimigración en el contexto español: El creciente protagonismo de lo punitivo en el control migratorio", 
en: LÓPEZ-SALA, Ana; GODENAU, Dirk (Coords.), Estados de contención, estados de detención. El control de la inmigración irregular en España (Barcelona, Anthropos), pp. 119-143.

CASSÀ, Núria (2015): Les visites familiars a presos com a element reductor de la reincidència (Barcelona, Centre d'Estudis Jurídics i Formació Especialitzada).

CASTILLO, Joaquina; RUIZ-GARCÍA, Marta (2010): "Mujeres extranjeras en las prisiones españolas. El caso andaluz", en: Revista Internacional de Sociología (Vol. 68.2), pp. 473-498.

CEJFE (2004): Variables de la concessió de la llibertat condicional (Barcelona, Centre d'Estudis Jurídics i Formació Especialitzada).

CEJFE (2010): Estrangers a les presons catalanes (Barcelona, Centre d'Estudis Jurídics i Formació Especialitzada).

CEJFE (2014): La llibertat condicional a Catalunya (Barcelona, Centre d'Estudis Jurídics i Formació Especialitzada).

CLEMMER, Donald (1940): The Prison Community (Nueva York, Holt, Rhineheart and Winston).

CUTIÑO, Salvador; NAKAHIRA, Masako, POZO, Federico; NAVARRO, Luis (2019): "Percepción de los internos en prisión sobre sus relaciones con los funcionarios según el módulo de residencia", en: Revista General de Derecho Penal (º31), pp. 1-38.

DAUNIS, Alberto (2009): El derecho penal como herramienta de control de la política migratoria (Granada, Comares).

DEPARTAMENT DE JUSTÍCIA (2015): Guia per al respecte a la diversitat de creences als centres penitenciaris de Catalunya (Collecció "Guies sobre la Diversitat Religiosa", 3, Departament de Justícia).

DE MARCOS, Florencio (2010): "Una aproximación al tratamiento penitenciario de los extranjeros en prisión", en: Diario la ley ( $\left.{ }^{\circ} 7410\right)$, pp. 1-12.

DOWNES, David (1988): Contrasts in Tolerance: Post-War Penal Policy in the Netherlands and England and Wales (Oxford, Clarendon Press).

ESCOBAR, Gonzalo (2010): "Extranjeros y prisiones", en: Revista de Estudios de la Justicia (12), pp. 261-277.

FERNÁNDEZ-BESSA, Cristina; BRANDARIZ, José Ángel (2016): “Transformaciones de la penalidad migratoria en el contexto de la crisis económica: El giro gerencial del dispositivo de deportación”, en: InDret Revista para el análisis del Derecho (4/2016), pp. $1-25$.

GALLEGO, Manuel; CABRERA, Pedro; RÍOS, Julián; SEGOVIA José Luis (2010): Andar $1 \mathrm{~km}$ en línea recta. La cárcel del siglo XXI que vive el preso (Madrid, Universidad Pontificia de Comillas).

GARCÍA-AÑÓN, José; BRADFORD, Ben; GARCÍA-SÁEZ, José Antonio; GASCÓN CUENCA, Andrés; LLORENTE, Antoni (2013): Identificación policial por perfil étnico en España. Informe sobre experiencias y actitudes en relación con las actuaciones policiales (Valencia, Tirant lo Blanch).

GARCÍA-ESPAÑA, Elisa (2001): Inmigración y delincuencia en España: Análisis criminológico (Valencia, Tirant lo Blanch).

GARCÍA-ESPAÑA, Elisa (2007): "Extranjeros presos y reinserción: un reto del siglo XXI", en: CEREZO, Anabel; GARCÍA-ESPAÑA, Elisa (Coords.), La prisión en España: una perspectiva criminológica, (Granada, Comares), pp. 101-134. 
GARCÍA-ESPAÑA, Elisa (2018a): Enfoque criminológico de las migraciones (Madrid, Editorial Síntesis).

GARCÍA-ESPAÑA, Elisa (2018b): "El arraigo de presos extranjeros. Más allá de un criterio limitador de la expulsión”, en: Migraciones (N44), pp. 119-144.

GARCÍA-ESPAÑA, Elisa; BECERRA, José; AGUILAR, Araceli (2012): Realidad y política penitenciarias (Málaga, Instituto Andaluz Interuniversitario de Criminología).

GONZÁLEZ SÁNCHEZ, Ignacio (2012): "La cárcel en España: mediciones y condiciones del encarcelamiento en el siglo XXI", en: Revista de Derecho Penal y Criminología

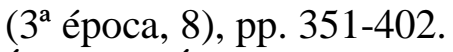

GONZÁLEZ SÁNCHEZ, Ignacio (2016): "La penalización de los migrantes: irregularidad y cárcel en la construcción del estado neoliberal", en: Migraciones (39), pp. 123-147.

IBÀÑEZ, Aina (2019): "Progresar hacia el régimen abierto: la visión de los profesionales”, en: Revista Española de Investigación Criminológica (17), pp. 128.

KAUFMAN, Emma (2012): "Finding foreigners: Race and the politics of memory in British prisons", en: Population, Space and Place (18.6), pp. 701-714.

KRUTTSCHNITT, Candace; DIRKZWAGER, Anja; KENNEDY, L. (2013): "Strangers in a strange land: coping with imprisonment as a racial or ethnic foreign national inmate", en: The British Journal of Sociology (Vol. 64.3), pp. 478-500.

LARRAURI, Elena (2016): "Antecedentes penales y expulsión de personas inmigrantes”, en: InDret Revista para el Análisis del Derecho (2/2016), pp. 1-29.

LARRAURI, Elena; ROVIRA, Martí y SALES, Albert (2017): "Qualitat de vida als centres penitenciaris i programes d'intervenció", en: Invesbreu Criminologia $\left(\mathrm{N}^{\circ} 74\right)$, pp. 2-5.

LIEBLING, Alison (2004): Prisons and their moral performance. Assisted by Helen Arnold. (Oxford, Clarendon Press).

LIEBLING, Alison (2013): “'Legitimacy under pressure' in high security prisons”, en: TANKEBE, Justice; LIEBLING, Alison (Eds.), Legitimacy and Criminal Justice: An International Exploration (Oxford University Press), pp. 206-226.

MARTÍ, Marta (2017): "El estudio de la calidad de vida en prisión. Una revisión bibliográfica de la investigación en España y principales planteamientos internacionales", en: InDret: Revista para el análisis del Derecho (3/2017), pp. 1-34.

MINISTERIO DEL INTERIOR (2019). Anuario Estadístico del Ministerio del Interior 2018 (Madrid, Ministerio del Interior, Secretaría General Técnica).

MONCLÚS, Marta (2008): La gestión penal de la inmigración (Buenos Aires, Del Puerto).

MONTERO, Ester y DURNESCU, Ioan (2016): “The pains of Romanian prisoners in Spanish prisons", en: Social Work Review (Vol. 15.4), pp. 31-42.

MULGREW, Roisin (2018): "The role of oversight in foreign-national only prisons: counteracting the disapplication of rehabilitation", en: Crime, Law and Social Change (70.1), pp. 77-92.

PAKES, Francis; HOLT, Katerine (2017): "Crimmigration and the prison: Comparing trends in prison policy and practice in England \& Wales and Norway", en: European Journal of Criminology (14.1), pp. 63-77. 
PHILLIPS, Coretta (2012): The multicultural prison: Ethnicity, masculinity, and social relations among prisoners (Oxford, Oxford University Press), pp. 169-203.

POZO, Federico; NAVARRO, Luis; NAKAHIRA, Masako; CUTIÑO, Salvador (2018): "Cara a cara con la cárcel. La visión de los presos sobre sus condiciones de custodia y resocialización en un centro penitenciario", en: Encrucijadas. Revista Crítica de Ciencias Sociales ( $\left.\mathrm{N}^{\circ} 16\right)$, pp. 1-24

POZO, Federico; NAVARRO, Luis; NAKAHIRA, Masako; CUTIÑO, Salvador (2020): “El desempeño relacional de la prisión. La valoración de los presos del trato y las relaciones con funcionarios de vigilancia y personal de tratamiento", en: Revista Española De Investigación Criminológica (18), pp. 1-29.

RÍOS, Julián Carlos; CABRERA, Pedro José (1998): Mil voces presas (Comillas, Universidad Pontificia de Comillas).

RODRÍGUEZ, Jorge; LARRAURI, Elena; GÜERRI, Cristina (2018): "Percepción de calidad de vida en prisión. La importancia de una buena organización y un trato digno", en: Revista Internacional de Sociología (Vol. 76.2), pp. 1-20.

RODRÍGUEZ YAGÜE, Cristina (2004): "Los derechos de los extranjeros en las prisiones españolas: legalidad y realidad", en: Revista General de Derecho Penal (2), p. 1-58.

ROVIRA, Martí; LARRAURI, Elena; ALARCÓN, Pau (2018): "La concesión de permisos penitenciarios: Una aproximación criminológica a distintas fuentes de variación", en: Revista electrónica de ciencia penal y criminología ( $\left.\mathrm{N}^{\circ} 20\right)$, pp. 1-26.

RUIZ-GARCÍA, Marta; CASTILLO, Joaquina (2014): "Experiences of Foreign Women in Spanish Prisons", en: Journal of Offender Rehabilitation ( $\left.\mathrm{N}^{\circ} 53\right)$, pp. 587-599.

SALES, Albert (2018): La calidad de vida de los internos extranjeros en el Centro Penitenciario Lledoners. Tesis defendida en la Universitat Pompeu Fabra. Disponible en: http://hdl.handle.net/10803/664018 [visitado el 20/10/2020].

SEGOVIA, Mikel (2020): "El Gobierno cederá prisiones a Euskadi a finales de año y la Seguridad Social en 2021". Disponible en: https://tinyurl.com/ygwudxyg [visitado el 21/04/2021].

SYKES, Gresham M. (1958[2007]): The Society of Captives: A Study of a Maximum Security Prison (Princeton, NJ, Princeton University Press).

UGELVIK, Thomas (2011) "The Hidden Food: Mealtime Resistance and Identity Work in a Norwegian Prison", en: Punishment and Society (13.1), pp. 47-63.

UGELVIK, Thomas (2015): "The incarceration of foreigners in European prisons", en: PICKERING, Sharon; HAM, Julie (Eds.), The Routledge Handbook on Crime and International Migration, (London, Routledge) pp. 107-120.

UGELVIK, Thomas; DAMSA, Dorina (2018): "The pains of crimmigration imprisonment: perspectives from a Norwegian all-foreign prison", en: British Journal of Criminology ( $\mathrm{N}^{\circ}$ 58), pp. 1025-1043.

VAN KALMTHOUT, Anton; HOFSTEE-VAN DER MEULEN, Femke H.; DÜNKEL, Frieder (2007): Foreigners in European prisons (Nijmegen, Wolf Legal Publishers).

VAN ZYL SMIT, Dirk; SNACKEN, Sonja (2013): Principios de Derecho y Política Penitenciaria Europea (Valencia, Tirant lo Blanch).

WARR, Jason (2016): "The deprivation of certitude, legitimacy and hope: Foreign national prisoners and the pains of imprisonment", en: Criminology and Criminal Justice (Vol. 16.3), pp. 301-318. 


\section{Anexo I. Resumen análisis de regresión logística: Coeficientes explicativos de las variables de control (signo del coeficiente $B$ y significación estadística)}

\section{Estándar de vida}

Condiciones de vida buenas

Prisión no está mal, decente

Prisión bien organizada

Necesario para mantenerse limpio

Ayuda con problemas médicos

No se queja de la comida

\section{Actividades}

No pasa más de 6hs sin actividades

Participa en actividades educativas

Tiene puesto de trabajo (talleres/destinos)

Programa de tratamiento

Apoyo a la reinserción

Ayudan a hacer planes para no delinquir

Explican qué hacer para progresar en grado

Clasificado en grado que corresponde

Ha disfrutado de permisos

Relaciones con el personal (diferencias de trato)

Las relaciones con personal son buenas

Recibe trato respetuoso

Recibe apoyo del personal si lo necesita

Recibe trato con amabilidad

Relaciones con el personal (diferencias decisorias)

Destinos distribuidos de forma justa

Normas aplicadas de forma justa

Respeto de derechos como interno

\section{Relaciones con otros internos}

No hay muchas peleas en módulo

Es difícil tener deudas

No siente miedo de ser golpeado o amenazado

No preocupa seguridad física

Contacto con el exterior

Puede recibir visitas con frecuencia

Puede mantener contacto frecuente con familia
Interno primario+**

Variables de control con efecto estadísticamente significativo

Interno primario+*; duración condena+**; tiempo en prisión$* * *$

Edad+*; consumo drogas-**; internado psiquiátrico-* Consumo drogas- $* * *$; abuso drogas- $* * *$; autolesión-**; tiempo en prisión-*

Consumo drogas-*; intento suicidio- $* *$

Edad+**

Edad-**; consumo drogas- $* * *$

Autolesión-*; internado psiquiátrico-***; interno primario+***

Abuso alcohol-*

Abuso drogas-*; abuso alcohol+**; internado psiquiátrico-

**; tiempo en prisión+*

Tiempo en prisión+**

Internado psiquiátrico-**

Duración condena-*; tiempo en prisión+*

Abuso drogas+*; duración condena+***; tiempo en prisión$* * *$

Tiempo en prisión+***

Edad+***; interno primario+**; duración condena-*

Edad+***; consumo drogas-**

Edad $+* * *$

Edad+*; internado psiquiátrico-*; interno primario+*

Edad+***; consumo drogas-**; abuso drogas-*

Edad+***; intento suicidio-*

Edad+**; internado psiquiátrico-*

Interno primario+**; tiempo en prisión-**

$-$

$-$

Abuso alcohol-*

*** Efecto estadísticamente significativo a nivel 0,$01 ; * * 0,05 ; * 0,1$ 